OPEN ACCESS

Edited by:

Maria Cristina D'Adamo,

University of Malta, Malta

Reviewed by:

Sirish Chandra Bennuri,

University of Arkansas for Medical

Sciences, United States

Yuying Liu,

The University of Texas Health Science Center at Houston,

United States

*Correspondence:

Rebecca S. Eshraghi

rebeccasherry@bellsouth.net

Received: 22 March 2018

Accepted: 27 July 2018

Published: 15 August 2018

Citation:

Eshraghi RS, Deth RC, Mittal R, Aranke M, Kay S-IS, Moshiree B and Eshraghi AA (2018) Early Disruption

of the Microbiome Leading

to Decreased Antioxidant Capacity and Epigenetic Changes: Implications

for the Rise in Autism.

Front. Cell. Neurosci. 12:256.

doi: 10.3389/fncel.2018.00256

\section{Early Disruption of the Microbiome Leading to Decreased Antioxidant Capacity and Epigenetic Changes: Implications for the Rise in Autism}

\author{
Rebecca S. Eshraghi*, Richard C. Deth ${ }^{2}$, Rahul Mittal ${ }^{3}$, Mayank Aranke ${ }^{3}$, \\ Sae-In S. Kay ${ }^{4}$, Baharak Moshiree ${ }^{1}$ and Adrien A. Eshraghi ${ }^{3}$ \\ ${ }^{1}$ Division of Gastroenterology, Department of Medicine, Miller School of Medicine, University of Miami, Miami, FL, \\ United States, ${ }^{2}$ Department of Pharmaceutical Sciences, College of Pharmacy, Nova Southeastern University, \\ Fort Lauderdale, FL, United States, ${ }^{3}$ Department of Otolaryngology, Miller School of Medicine, University of Miami, Miami, \\ FL, United States, ${ }^{4}$ Dr. Kiran C. Patel College of Osteopathic Medicine, Nova Southeastern University, Fort Lauderdale, FL, \\ United States
}

Currently, 1 out of every 59 children in the United States is diagnosed with autism. While initial research to find the possible causes for autism were mostly focused on the genome, more recent studies indicate a significant role for epigenetic regulation of gene expression and the microbiome. In this review article, we examine the connections between early disruption of the developing microbiome and gastrointestinal tract function, with particular regard to susceptibility to autism. The biological mechanisms that accompany individuals with autism are reviewed in this manuscript including immune system dysregulation, inflammation, oxidative stress, metabolic and methylation abnormalities as well as gastrointestinal distress. We propose that these autismassociated biological mechanisms may be caused and/or sustained by dysbiosis, an alteration to the composition of resident commensal communities relative to the community found in healthy individuals and its redox and epigenetic consequences, changes that in part can be due to early use and over-use of antibiotics across generations. Further studies are warranted to clarify the contribution of oxidative stress and gut microbiome in the pathophysiology of autism. A better understanding of the microbiome and gastrointestinal tract in relation to autism will provide promising new opportunities to develop novel treatment modalities.

Keywords: autism, oxidative stress, epigenetics, gut microbiota, dysbiosis

\section{INTRODUCTION}

Autism spectrum disorder (ASD) is a pervasive neurodevelopmental disorder characterized by impaired social communication and repetitive as well as stereotyped patterns of behavior. Although autism is mostly recognized by means of behavioral features and autism related disabilities, co-morbid factors such as distinct gut microbial composition, heightened immune response and gastrointestinal abnormalities have been observed (Rose et al., 2018). In addition to these characteristics, alteration in the composition of the gut microbiome has been observed in ASD individuals (Parracho et al., 2005; Finegold et al., 2010; Kang et al., 2018). Multiple factors can 
change the constitution of the microbiome such as vaginal flora at birth, cesarean section vs. vaginal delivery, breast milk vs. bottle feeding, early nutrition and environmental exposures, as well as antibiotics use, which has one of the most significant effects on microbial ecology (Martin et al., 2016; Bilbo et al., 2017) (Figures 1, 2). Among other consequences, early disruption of a developing gut microbiota can adversely affect antioxidant production (Mardinoglu et al., 2015; Gyuraszova et al., 2017).

Besides antioxidant production, the nature of the microbial community in the gastrointestinal (GI) tract can affect the risk of obesity, diabetes, colon cancer, and autoimmunity (Turnbaugh et al., 2006; Sobhani et al., 2011; Qin et al., 2012; Thursby and Juge, 2017). It is believed that an infant's gut is sterile until the first exposure to microbes at birth when the baby passes through the birth canal and gets coated with microbes from the mother, or swallows microbes from the mother's vagina (Macpherson et al., 2017). After these initial exposures, the infant is continuously exposed to bacteria through the mother's breast milk, food consumption and the environment (Jost et al., 2013; Chu et al., 2016; Gregory et al., 2016). Over time the microbiome becomes individualized, although the composition is strongly dependent on parents and even ancestors (Gibiino et al., 2017). No two individuals share the same microbiome composition, not even identical twins (Turnbaugh et al., 2009).

The GI microbiota can play a crucial role in bidirectional communication between the gut and the brain (Mittal et al., 2017; de la Fuente-Nunez et al., 2018). The gut microbiota influences brain function through the neuroendocrine, neuroimmune and autonomic nervous systems (Kim et al., 2018; Sylvia and Demas, 2018). The aim of this article is to review recent advancements in understanding how the disruption of gut microbiota can alter antioxidant homeostasis in the GI tract and how that can increase the risk of developing autism.

\section{BIOLOGICAL MECHANISMS ASSOCIATED WITH AUTISM}

\section{Immune System Abnormalities}

The gut microbiota plays an important role in shaping host immunity. Gut dysbiosis has been associated with immune system abnormalities and has been implicated in the pathogenesis of inflammatory diseases such as systemic lupus erythematosus (SLE) and rheumatoid arthritis (RE) (Liu et al., 2013; Hevia et al., 2014; Zhang et al., 2015; Luo et al., 2018). In addition to these disorders, gut dysbiosis leading to immune system abnormalities has been hypothesized to play a crucial role in the pathophysiology of ASD.

Improperly activated immune system abnormalities such as neuroinflammation, pro-inflammatory cytokines, immunoglobulins, immune cellular activation and autoimmunity are significant risk factors in ASD (Goines and Van de Water, 2010; Morgan et al., 2010; Edmiston et al., 2017; Fluegge, 2017; Masi et al., 2017; Wong and Hoeffer, 2017). Dysregulation of T cell responses can lead to activation of meningeal macrophages and glia cells with an adverse effect on brain function (Figure 3). A study of post-mortem brain tissues from individuals with
ASD demonstrated CNS inflammation, a significantly higher incidence of pro-inflammatory and Th1 cytokines than control group (Morgun et al., 2015). There is evidence of autoimmunity with circulating antibodies directed toward brain proteins in individuals with autism ( $\mathrm{Li}$ et al., 2009). Finally, cell-mediated immunity is impaired in ASD, as shown by low numbers of CD4 cells and associated T-cell polarity with an imbalance of Th1/Th2 subsets toward Th2 (Filiano et al., 2015). Deviations in the level of natural killer (NK) cells and macrophages have been observed in individuals with autism compared to controls (Cohly and Panja, 2005; Vojdani et al., 2008). Taken together these studies suggest that immune system abnormalities are prevalent in ASD patients. However, further studies using larger sample sizes are required to confirm and understand the role of immune system abnormalities underlying the pathophysiology of ASD.

\section{Impaired Methylation and Oxidative Stress}

In addition to immune system abnormalities, altered DNA methylation patterns have been observed in ASD patients. DNA methylation is a highly complex and dynamic process enabling epigenetic regulation of gene expression (Segen, 2005; Chen et al., 2017; Krejcova et al., 2017; Zhang et al., 2017; Kim et al., 2018; Meehan et al., 2018). Epigenetic regulation provides a mechanism by which the body can adaptively deal with stress as well as infections and toxins. It is a fundamental cellular pathway that supports detoxification while regulating inflammation and balancing the action of neurotransmitters (James et al., 2004; MacDonald and Roskams, 2009; McCall et al., 2010; Berk et al., 2011; Hedrich, 2017; Samanta et al., 2017). It is now apparent that methylation-dependent epigenetic regulation is the fundamental driving force behind development, including both prenatal and postnatal development. Consequently, those functions of the GI tract and its microbiome that support methylation capacity are essential for normal development. Vitamin B12 (cobalamin) and folic acid (folate) are two of the most important nutritional factors for methylation and their efficient absorption is essential for normal epigenetic regulation and postnatal development (DeVilbiss et al., 2015; Athanasopoulos et al., 2016; Crott, 2017). Folate is produced by bacteria for their own metabolic needs, but only certain bacterial strains (e.g., Bifidobacterium and Lactobacillus) are capable of producing vitamin B12, setting up competition between microbes and intestinal epithelial cells in the distal ileum, the primary site of B12 absorption (Degnan et al., 2014). There are specific transport mechanisms for intestinal uptake of B12 bound to its carrier protein intrinsic factor and pathological GI conditions such as inflammation and/or oxidative stress may adversely affect B12 absorption by their effects on the transport process.

The alteration in genetic composition can also influence methylation and nutritional absorption including vitamin B12 and folic acid absorption. A major genetic determinant of methylation capacity is the presence or absence of single nucleotide polymorphisms (SNPs) in the gene for 5,10methylenetetrahydrofolate reductase (MTHFR) (Yuan et al., 2017). MTHFR catalyzes formation of 5-methyltetrahydrofolate, 


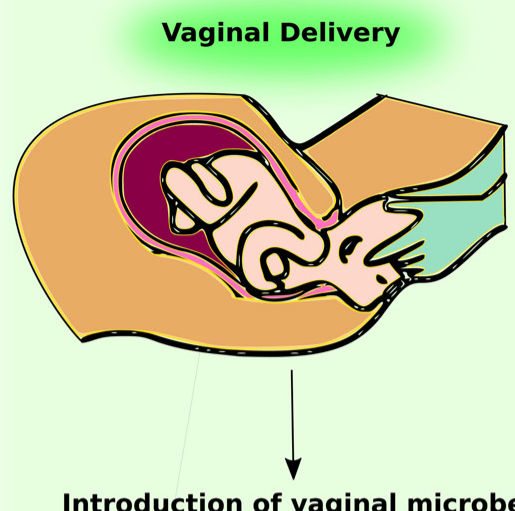

Introduction of vaginal microbes

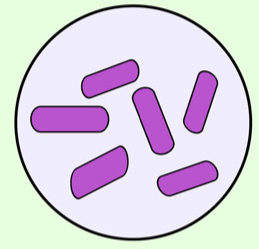

Lactobacillus

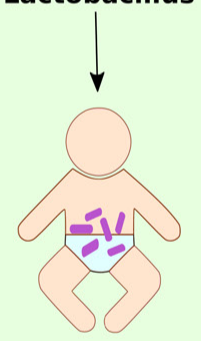

Normal gut microbe introduction

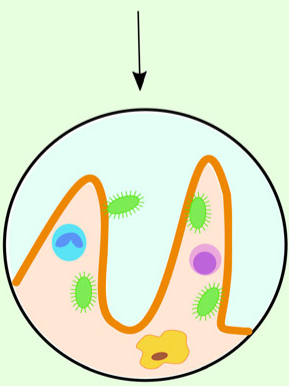

- Normal intestinal microbial colonization - Proper immune system development v.s.

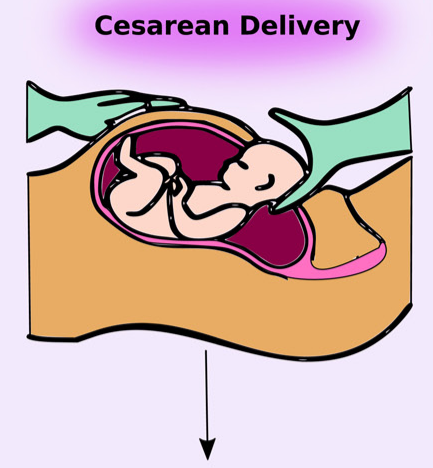

Introduction of skin microbes

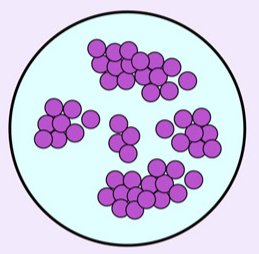

Staphylococcus

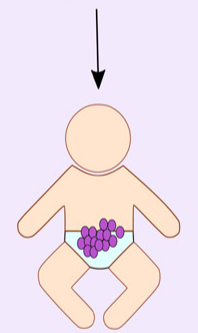

Abnormal gut microbe introduction

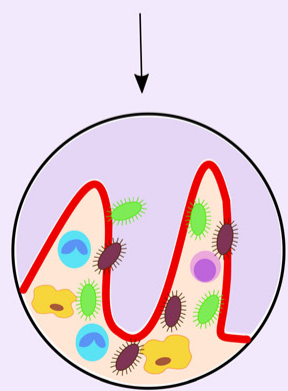

- Abnormal intestinal microbial colonization - Disrupted immune system development - Increased risk for atopic disease, asthma, celiac disease, allergic reaction

FIGURE 1 | Intestinal microbial introduction by vaginal delivery vs. Cesarean delivery. In vaginal delivery, infants obtain Lactobacillus via the vaginal canal. This promotes normal intestinal microbial colonization and development of a competent gut immune system. In contrast, in Cesarean delivery, infants obtain skin microbes, including Staphylococcus. This abnormal gut microbe introduction leads to altered intestinal microbial colonization and increases the risk of immunologic disorders.

the source of methyl groups for the B12 and methylfolatedependent enzyme methionine synthase (MS), which converts homocysteine (HCY) to methionine (MET) (Wang and Jin, 2017). MS activity exerts general control over hundreds of methylation reactions, including DNA methylation, because it increases the level of the universal methyl donor $S$-adenosylmethionine (SAM) while at the same time decreasing the level of $S$-adenosylhomocysteine (SAH), which is an 

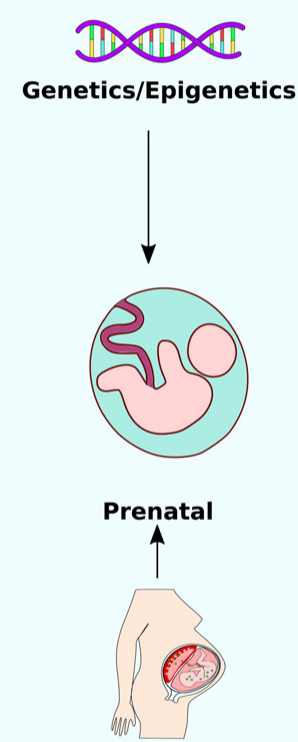

Maternal microbes /

Intrauterine contamination

- Bifidobacterium

- Lactobacillus

- Enterococcus

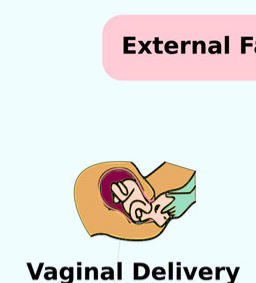

- Lactobacillus

- Prevotella

- Sneathia

$\downarrow$

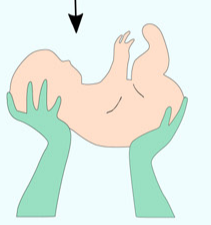

Birth
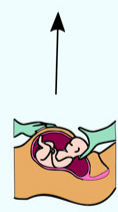

C-Section

- Staphylococcus - Corynebacterium

- Propionibacterium

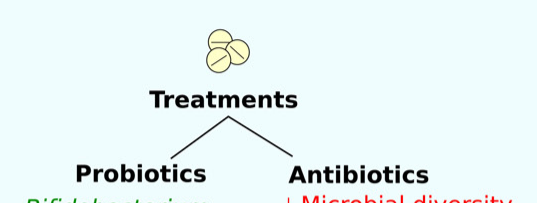

- Bifidobacterium - $\quad \downarrow$ Microbial diversity

- Lactobacillus
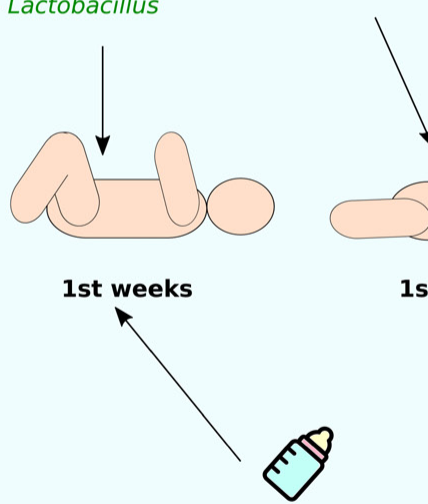

Type of Feeding

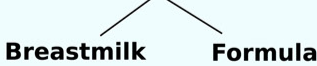

- Bifidobacterium - Enterobacteriaceae

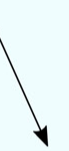

Weaning \& Foods chosen

1st months

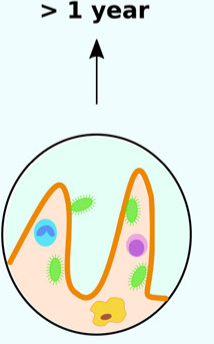

Development of Adult-like microbes

FIGURE 2 | External factors affecting the intestinal microbiota of infants. Through infant developmental stages, multiple factors affect the constitution of intestinal microbiota. Beneficial modifications are highlighted in green and negative alterations are highlighted in red. At the prenatal stage, genetic factors or maternal microbes and intrauterine contamination can affect intestinal colonization. At birth, the delivery method is the main determining factor of gut microbiota. Type of feeding and probiotic/antibiotic treatments at weeks and months can contribute to alteration of intestinal microbes. Approximately at 1 year of age, infants accomplish adult-like gut microbe colonization.

inhibitor of methylation reactions and the precursor molecule to homocysteine in the methionine cycle. There are two relatively common SNPs in MTHFR, C677T, and A1298C, each of which can decrease enzyme activity (Berk et al., 2011; Rai, 2017), especially in homozygous individuals (i.e., carry two copies). The C677T SNP polymorphism has been associated with autism in Caucasian and Asian populations (Rai, 2016).

Besides genetics, methylation activity is highly sensitive to antioxidant status (García-Giménez et al., 2017), in part because the B12 cofactor in MS is very easily oxidized. When mitochondrial aerobic metabolism is high, the production of reactive oxygen by-products can exceed the available amount of antioxidant, leading to a condition of oxidative stress (inadequate antioxidant capacity). Glutathione (GSH) is the primary intracellular antioxidant for all cells and its formation has been linked to MS activity. When vitamin B12 gets oxidized during oxidative stress, the lower MS activity diverts more HCY to increase GSH synthesis, helping to resolve the oxidative stress. In this manner vitamin B12 serves as a sensor of antioxidant status and helps to replenish it as needed (Herrmann et al., 2001).
When oxidative stress turns MS off, methylation activity (including DNA methylation), is decreased and consequential changes in gene expression can also help to resolve the oxidative stress.

The GI microbiome can exert an important influence over systemic antioxidant status (Wang et al., 2017; Bonfili et al., 2018). A study examined metabolic differences between germfree and conventionally raised mice and found that the presence or absence of a microbiome altered gene expression in the host GI tissues (Mardinoglu et al., 2015). Specifically, it was found that there was a significantly lower expression of genes involved in the synthesis of GSH from cysteine in GI tissues of conventionally raised mice, especially in the ileum, and this decrease was associated with lower absorption of a number of amino acids, including methionine. Absorption of the sulfur amino acid cysteine and its oxidized form cysteine is crucial to supply the body with the material to synthesize GSH. It is noteworthy that the cysteine transporter EAAT3 (excitatory amino acid transporter 3 ) is most highly expressed in the ileum, especially the distal ileum, the site of vitamin B12 absorption 


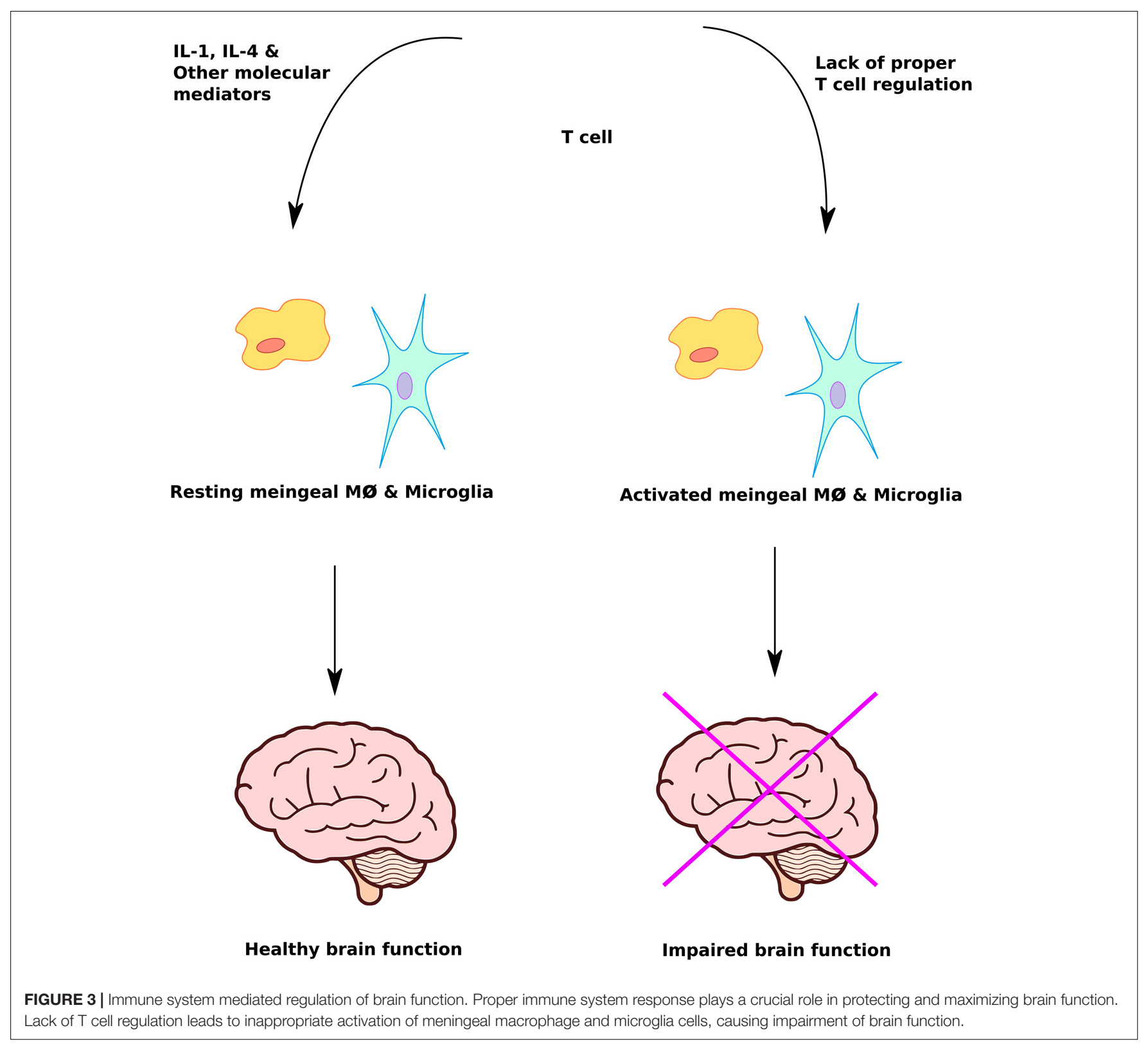

(Iwanaga et al., 2005; Aoyama and Nakaki, 2013; Aoyama and Nakaki, 2015; Bjørn-Yoshimoto and Underhill, 2016). This co-localization facilitates postnatal epigenetic programming in response to the level of antioxidant (Waly et al., 2012).

A number of studies have reported the presence of oxidative stress in autism, associated with a decreased plasma level of GSH (Ghanizadeh et al., 2012; Gu et al., 2015; El-Ansary et al., 2017). GSH is one of the most important detoxifying agents and is composed of three amino acids, cysteine, glycine, and glutamate (Awasthi et al., 2017; McBean, 2017). The highest concentration of GSH is in the liver, whereas brain levels are low, and depletion of glutathione leads to oxidative stress. Oxidative stress occurs when there is an imbalance between the production of reactive oxygen and a biological system's ability to detoxify or repair oxidative damage. Children with autism have shown to have increased oxidative stress and impaired DNA methylation capacity (James et al., 2004; Frustaci et al., 2012). Indeed, the levels of oxidative stress and impaired methylation can identify autistic vs. neurotypical subjects with an accuracy of 97\% (Howsmon et al., 2017).

\section{Gastrointestinal Distress}

Among other complications, gastrointestinal problems are by far the most common and GI disease is more prevalent in individuals with autism (Hsiao, 2014; Isaksson et al., 2017; Holingue et al., 2018). GI symptoms occur in about half of children with ASD, and the prevalence increases as children get older (Chaidez et al., 2014). Moreover, the severity of autism symptoms is related to the occurrence of problems in the gastrointestinal tract (Wang et al., 2011). Reported problems 
included chronic constipation, chronic diarrhea, abdominal pain, gastroesophageal reflux disease (GERD), gas and bloating. A multicenter study of over 14,000 individuals with ASD revealed a higher prevalence of inflammatory bowel disease (IBD) and other GI disorders in patients with ASD as compared to controls (Kohane et al., 2012). The digestive tract of children with autism revealed substantial differences compared to neurotypical children including abnormal intestinal permeability, inflammation and different composition of intestinal microbes.

\section{Abnormal Intestinal Permeability}

While studies have shown inconsistent findings (Kushak et al., 2016), children with autism may exhibit abnormal intestinal permeability referred to as "leaky gut syndrome" (D'Eufemia et al., 1996; Turck and Michaud, 2008; de Magistris et al., 2010) (Figure 4). In case of a leaky gut, the defensive barrier to prevent substances in the GI tract from entering into the blood stream is compromised and is therefore referred to as "leaky" (Liu et al., 2005). With loss of the usual barrier of the gut lining, nutrient absorption can be compromised and toxins are able to enter into the blood stream. Abnormal intestinal permeability/leaky gut, is increasingly recognized as an important contributor for many different conditions, including autism, demonstrated in experimental animal models as well as in human subjects (Hsiao et al., 2013; Buscarinu et al., 2018). Increased gut permeability as indicated by increased fluorescein isothiocyanatelabeled dextran (FITC-dextran) levels in the plasma following oral gavage was observed in a BTBR mouse model of autism (Coretti et al., 2017). In agreement with these results, significantly decreased mRNA levels of occludin and zonulin was observed in male BTBR mice with a similar pattern in female mice although the levels were not significant compared to prosocial C57BL/6j (C57) mice. Occludin and zonulin are tight junction proteins that help in maintaining gut integrity (Wang et al., 2000; Weber, 2012; Sturgeon et al., 2017). In addition, gut dysbiosis, behavior alterations (demonstrated via differences in three chamber paradigm, marble burying and spontaneous selfgrooming tests) and increased mRNA levels of proinflammatory markers such as CD11c, IL-10, IL-6, and TNF-alpha were observed in both sexes of BTBR mice compared to C57 mice. Bacteroides, Parabacteroides, Sutterella, Dehalobacterium, and Oscillospira genera, based on phylotypic evidence identified by applying the metagenomic biomarker discovery approach of LEfSe [linear discriminant analysis (LDA) effect size (LEfSe) method], were suggested to be associated with the pathological traits observed in this BTBR mouse model of autism (Coretti et al., 2017). This BTBR mouse model can serve as a valuable tool to understand the role of microbiota in interaction of gutbrain axis during autism as well as to develop novel treatment modalities based on alteration of gut microbiota.

Besides experimental animal models, altered intestinal permeability has been observed in human autism patients. A study reported intestinal permeability in 9 out of 21 autistic patients (43\%) but in none of the 40 control subjects (D'Eufemia et al., 1996). In this study patients' ages ranged from 4 to 16 years comprising 15 males and 6 females. Another study reported a high percentage of abnormal intestinal permeability values among patients with autism (36.7\%) and their first-degree relatives $(21.2 \%)$ compared with normal subjects (4.8\%). Patients with autism on a reported gluten-casein free diet had significantly lower intestinal permeability (de Magistris et al., 2010). Further studies using larger number of autism subjects are warranted to understand how abnormal intestinal permeability/leaky gut leads to altered behavioral manifestations observed in autism. These future investigations should also take into account the differences between childhood and adulthood manifestations of abnormal intestinal permeability/leaky gut and their contribution to the development of ASD or its severity.

\section{Inflammation}

Maternal immune activation (inflammation) can contribute to behavioral abnormalities associated with neurodevelopment in both primate and rodent offspring (Smith et al., 2007; Malkova et al., 2012; Bauman et al., 2014; Machado et al., 2015). The exposure of fetuses to maternal inflammation thus increases the likelihood of developing autism in humans. However, further clinical studies using large cohorts of autism and control subjects are warranted to decipher the precise contribution of maternal inflammation in predisposition to ASD.

Inflammation has been observed in autism patients. It was shown that 48 out of $52(92.3 \%)$ children with regressive autism exhibited inflammation in the upper and/or lower GI tract, and intestinal biopsies in children with regressive autism indicated a novel lymphocytic enterocolitis with autoimmune features (Ashwood et al., 2003). The incidence and prevalence of pediatric IBD in the United States are estimated at 10 per $100,000(0.01 \%)$ and $100-200$ per 100,000 (10-20\%) respectively (Rosen et al., 2015). The causes for gut inflammation are complex and multiple, but, in general, the same factors that cause leaky gut can trigger inflammation and vice versa. A lack of diverse gut bacteria was indicated by a study in which stool samples of children with autism and GI issues showed distinct and less diverse gut microbial composition, specifically a reduced abundance in the genera Prevotella, Coprococcus, and unclassified Veillonellaceae (Kang et al., 2013). In fact, the severity of the autistic characteristics correlated with the diversity and prevalence of some specific gut microbes such as Firmicutes spp.

\section{Different Intestinal Microbes and Gut Flora}

A number of studies have demonstrated that gut microbe composition is altered in autism subjects compared to normal individuals (Parracho et al., 2005; Finegold et al., 2010; Strati et al., 2017; Kang et al., 2018). A study demonstrated that autistic subjects had significantly lower amounts of three bacteria, Prevotella, Coprococcus, and Veillonellaceae (Kang et al., 2013). The higher levels of Clostridium, Bacteroides, Desulfovibrio, Caloramator, and Sarcina have also been observed in ASD patients compared to normal control individuals (Finegold et al., 2002, 2010; Adams et al., 2011; Finegold, 2011; De Angelis et al., 2013). A relative lower abundance of Feacalibacterium prausnitzii and Haemophilus parainfluenzae has been observed in feces of children with ASD compared to neurotypical controls. A study 


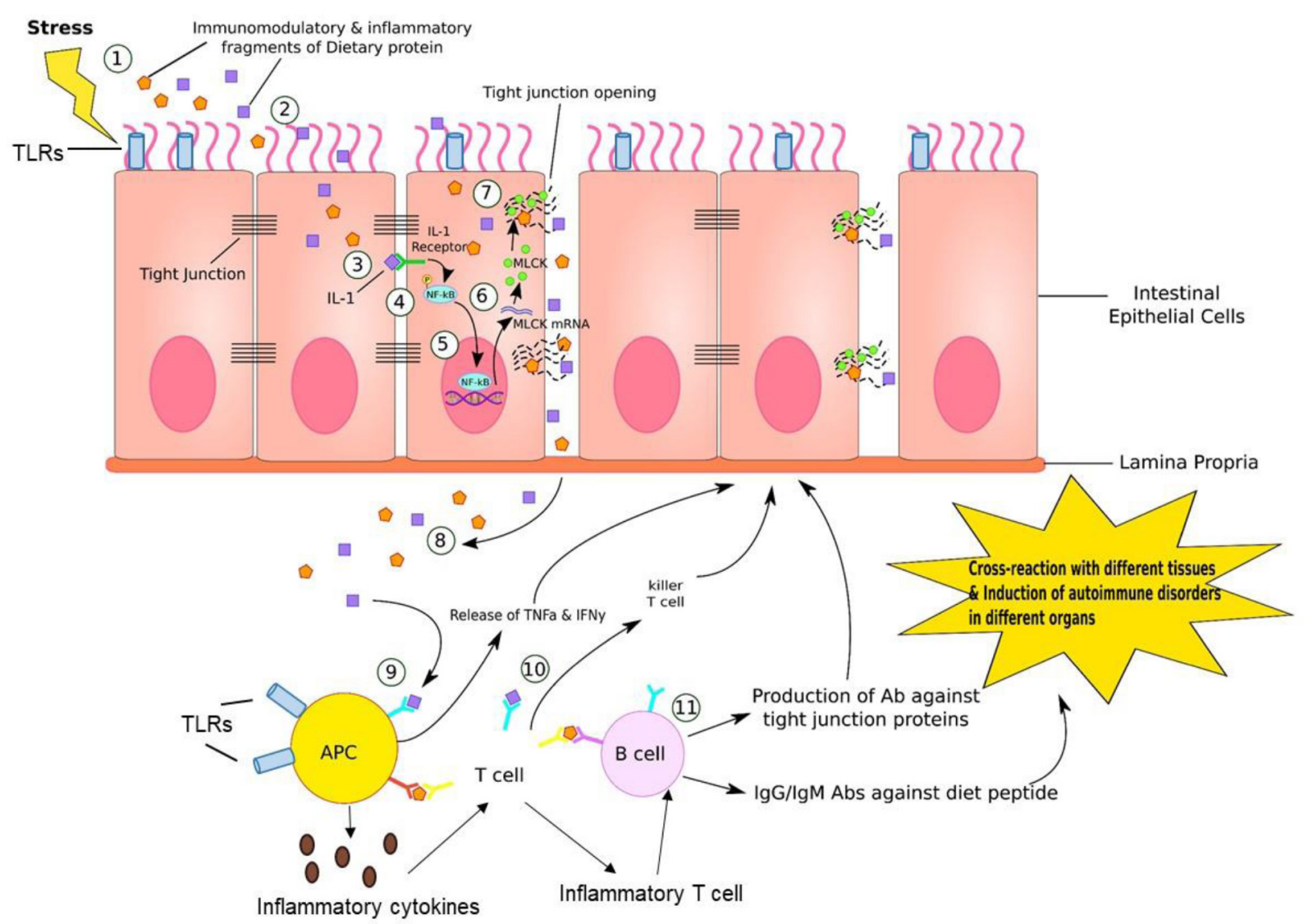

FIGURE 4 | Gut-brain inflammation. (1) Stress, such as medications, neurotransmitters, enzymes, neuropeptides, intestinal flora, or immune dysregulation generates immunomodulatory and inflammatory fragments of dietary proteins. (2) These fragments can diffuse into endothelial cells lining the GI tract. (3) IL-1, which is one of the product of fragment of dietary proteins bind to IL-1 receptor on the lateral border of adjacent epithelial cell. (4) This IL-1/L-1 receptor complex phosphorylates NF-kB. (5) Activated NF-kB further binds to DNA sequence in nucleus of endothelial cell, inducing transcription of MLCK (myosin-light chain kinase) mRNA. (6) MLCK mRNA travels to cytosol and is translated into MLCK proteins. (7) MLCK proteins bind to and open up the tight junction, where dietary fragment proteins are released into paracellular space. (8) These particles are further released into reticular tissue. (9) APC recognizes this dietary fragment and presents to T cells. (10) T cells generate killer T cell attacking epithelial cells that contain these inflammatory dietary fragments. (11) B cells are activated by $T$ cells presenting the dietary fragment. In response, B cells generate antibodies against tight junction proteins, IgG and IgM antibodies against diet peptides. This leads to cross-reaction in various tissues and induction of autoimmune disorders in different organs. In addition, antigen-presenting cells (APC) such as dendritic cells (DCs) can produce proinflammatory cytokines that educate naive CD4+ T cells into inflammatory T cells that can help B cell maturation to produce antibodies.

showed a significant increase in the Firmicutes/Bacteroidetes ratio in autism patients due to a reduction of the Bacteroidetes relative abundance (Strati et al., 2017). At the genus level, there was a decrease in the relative abundance of Alistipes, Bilophila, Dialister, Parabacteroides, and Veillonella whereas there was significant increase in the prevalence of Collinsella, Corynebacterium, Dorea, and Lactobacillus in autistic subjects. Further, there was abundance of bacterial taxa belonging to Escherichia/Shigella and Clostridium cluster XVIII in constipated autistic individuals. The prevalence of the fungal genus Candida was more than double in the autistic than neurotypical subjects. However, this difference in fungal numbers was only partially significant between autistic and neurotypical subjects.

Besides above-mentioned microbes, Sutterella, a genus of anaerobic Gram-negative bacteria within the Proteobacteria phylum, has also been implicated in the pathophysiology of ASD. The biopsies taken from the GI tract of ASD children with
GI disturbances demonstrated significantly higher prevalence of Sutterella species compared to control group (Williams et al., 2012). Another study also showed increased prevalence of Sutterella species as well as Ruminococcus torques, in the feces of children with ASD as compared to control group (Kang et al., 2013). Further still, a 2012 study showed higher concentrations of short chain fatty acids and ammonia in stool samples ASD children as compared with controls, suggesting altered fermentation processes and utilization of fermentation products in children with ASD (Wang et al., 2012). Although these studies clearly demonstrate that gut microbiota composition is altered in ASD patients, the body of literature in this space is still nascent and other studies suggest that the differences in the microbiomes of neurotypical children and children with ASD are either only partially significant or inconclusive (Gondalia et al., 2012; Son et al., 2015). Further studies using larger sample sizes and microbial detection techniques that are more sensitive 
in differentiating bacteria at the species level, are required to understand the precise contribution of this altered microbiota in predisposition to ASD.

\section{ANTIBIOTIC INDUCED SHIFTS IN THE MICROBIOME}

One of the factors responsible for the alteration of microbe composition as discussed above is the use of antibiotics. Antibiotics significantly shift the structure of the microbial community (Dethlefsen et al., 2008; Simon et al., 2015), changing the metabolic status of the gut (Ponziani et al., 2016). Some of the changes caused by antibiotics are transient and can be reversed at the end of the treatment, while others seem irreversible. Most importantly, it has been observed that gut bacteria present a lower capacity to produce proteins, as well as display deficiencies in key activities, during and after the antibiotic treatment. For instance, antibiotics decrease the ability to absorb iron, to digest certain foods and to produce essential molecules (Pérez-Cobas et al., 2013). Previously it was assumed that short-term antibiotic treatment would alter gut microbe composition only for a short time, however, this is not the case (Jernberg et al., 2010). Even a relatively short course of antibiotics can lead to alteration in gut microbiota, which in turn can lead to severe consequences such as inflammation, immune dysregulation, allergies, infections, cardiovascular diseases, diabetes, metabolic issues, GI disease such as Crohn's, IBD, yeast overgrowth, chronic constipation and diarrhea (Jernberg et al., 2007; Yang et al., 2009; Ubeda et al., 2010; Sobhani et al., 2011; Buffie et al., 2012; Rutten et al., 2015; Lau et al., 2017; Ni et al., 2017).

In 2010 there were nearly 23 million courses of Amoxicillin or Augmentin prescribed to children in the United States and more than 6.5 million of those courses were for children under the age of two (Chai et al., 2012; Blaser, 2014). Studies have shown that children with autism have had significantly more ear infections than control groups, leading to more antibiotic prescriptions (Niehus and Lord, 2006; Adams et al., 2016; Leung and Wong, 2017). Furthermore, another study showed that 34.5\% of children with autism had used extensive and repeated broadspectrum antibiotic treatments ( $>6$ courses) compared to control group ( $0 \%$ with more than 6 courses) (Parracho et al., 2005). In fact, a higher proportion of $54.5 \%$ of the children with autism had received more than six courses of antibiotics suggesting frequent over-prescription of antibiotics. Further prospective studies are warranted to understand how the overuse of antibiotics in the 1st years of life might disrupt the gut-brain axis and lead to the development of future neurological disorders including autism.

\section{MICROBIOME AND ANTIBIOTIC USE IN INFANCY AS WELL AS EARLY CHILDHOOD}

A baby's first exposure to the natural microbial world occurs during vaginal delivery (Martin et al., 2016). A woman's vaginal flora carries lactobacilli bacteria, which make the vaginal canal more acidic, a milieu that helps in establishing defense against pathogenic bacteria (Collado et al., 2016). In contrast, cesarean delivery is associated with long-term differences in the intestinal flora (Neu and Rushing, 2011). The primary gut flora in infants born via C-section is disturbed for up to 6 months after birth (Grönlund et al., 1999; Biasucci et al., 2008), and children born via $\mathrm{C}$-section have less protection against pathogenic invaders than infants born via vaginal delivery (Huurre et al., 2008; Biasucci et al., 2010). Currently the CDC estimates that more than $32 \%$ of babies in the United States are born via C-section (Centers for Disease Control and Prevention [CDC], 2014).

The first microbes that colonize the infants gut set the stage for a more adult-like microbiota in later years. Research has confirmed that delivery mode shapes the acquisition and structure of the initial microbiota of newborns (Biasucci et al., 2008) (Figure 1). Infants born via vaginal delivery displayed bacterial communities resembling their own mother's vaginal microbiota, dominated by Lactobacillus, Prevotella, or Sneathia spp., while babies born via C-section harbored bacterial communities similar to those found on the skin surface, dominated by Staphylococcus, Corynebacterium, and Propionibacterium spp. This finding would explain in part why babies born via $\mathrm{C}$-section are more vulnerable to certain pathogens, making them more susceptible to infections. It is estimated that 64 to $82 \%$ of reported cases of methicillin-resistant Staphylococcus aureus (MRSA) skin infections in newborns occurred in Cesarean-delivered infants (Centers for Disease Control and Prevention [CDC], 2006).

After birth, nutrition and environment play crucial roles in determining the baby's microbial constitution. Right after birth the baby instinctively reaches for the mother's nipple, bringing together the lactobacilli from the birth process in contact with the milk. Lactobacilli and other lactic acid producing bacteria break down lactose, the sugar in milk that converts into energy. Also, for the first few days after birth, the breasts of the mother produce colostrum. Colostrum contains antibodies to protect the newborn against disease, and contains less fat but delivers more protein than mature milk. The immune-protective properties of colostrum are crucial for early life. It contains numerous antibodies called "secretory immunoglobulin" (IgA) that help protect mucous membranes in the throat, lungs, and intestines. Leukocytes are also present in large numbers, which begin protecting the infant from harmful viruses and bacteria. Colostrum further enhances the healthy gut bacterial constitution by providing more beneficial bacteria. Since the newborn's digestive tract is still very immature, colostrum delivers its nutrients in a very concentrated low-volume form; its mild laxative effect encourages passing of the baby's first stool (Godhia and Patel, 2013).

The lactating mother's milk microbiome changes and varies according to the delivery mode and the maternal weight. Breast milk from women who gave birth via cesarean section is less diverse in bacterial composition than the breast milk in mothers who gave birth via vaginal delivery (Urbaniak et al., 2016). This discrepancy suggests that hormonal signals during the vaginal birth process may influence the diversity of microbes in breast milk (Cabrera-Rubio et al., 2012). As soon as milk production 
begins, the nursing baby will continue to receive the mother's microbes, allowing the mother's beneficial gut bacteria to be directly transferred to the neonate's gut via her breast milk. Indeed, the same strains of Bifidobacterium breve and several types of Clostridium bacteria are present in neonates as the mother (Jost et al., 2014).

In addition to above discussed factors, antibiotics can also play a crucial role in changes in the gut microbiome. The age of first exposure to antibiotics is very important for the future overall health of many individuals. Early colonization of healthy, beneficial gut bacteria is vitally important to maintain gut homeostasis, but the use of antibiotics during infancy can drastically alter the microbiome. Young children are the most vulnerable to the use and over-use of antibiotics. By the age of three, $80 \%$ of children have suffered at least one acute infection of the middle ear for which antibiotics are prescribed and more than $40 \%$ of children experience at least six of these acute infections of the middle ear by age seven (Blaser, 2014).

At birth the brain is only $25 \%$ wired, by the age of one it is about $75 \%$ wired and by the age of three the brain is wired up to $90 \%$ (Chédotal and Richards, 2010). At the same time, microbial colonization is actively taking place, setting the stage for future digestive health outcomes, as well as mental health and well-being. Only recently have we begun to understand the role of the early-life gut microbiota in the development of immune-mediated, metabolic, and neurological diseases. The human microbiome develops from birth until about the age of three, and antibiotics use during these formative years can disrupt the process (Arrieta et al., 2014). Recent research has shown that the immune system of infants is also in development during early years and not inborn as previously assumed (Simon et al., 2015). In a twin study, researchers dispelled the belief that the body's immune system is genetically programmed (Brodin et al., 2015). Since gut microbes regulate the immune system, antibiotic use in the 1st years of life can crucially impact maturation of the immune system. Further investigations using larger cohorts are warranted to understand how the antibiotic usage during infancy and early childhood leads to alterations in gut microbiota affecting gut-brain axis and hence, may increase predisposition to ASD.

\section{GUT - BRAIN CONNECTION AND THE BLOOD-BRAIN BARRIER}

As discussed earlier, the enteric nervous system provides bidirectional communication between gastrointestinal cells and the central nervous system (Mittal et al., 2017) (Figure 5). Moreover, gut microbiome alterations can unbalance gastrointestinal immune responses and influence distal effector sites, leading to CNS disease including demyelination and affective disorders (Ochoa-Repáraz and Kasper, 2014; MoyaPérez et al., 2017). Serotonin and inflammation can have a significant influence on the functioning of the gut-brain connection. In addition, gut microbes can also influence the integrity of blood-brain barrier as discussed below.

\section{Serotonin: The Neurotransmitter in the Gut}

Serotonin is a neurotransmitter regulating many functions of the human body, such as mood, sleep, appetite, temperature regulation, learning and memory and social behavior (Blanchard and Meyza, 2017; Brummelte et al., 2017; Gasparini et al., 2017). Serotonin is also involved in various functions of the cardiovascular, musculoskeletal and endocrine systems (Young, 2007; Elliott et al., 2008; Ayme-Dietrich et al., 2017; Shively et al., 2017). A deficiency in serotonin levels leads to many symptoms that most individuals with autism exhibit, such as anxiety, poor sleep, inability to focus, agitation, mood swings, and depression (Whitaker-Azmitia, 2001; Olivier, 2015; Blanchard and Meyza, 2017).

While $90 \%$ of serotonin is produced in the gut, it is also released in the CNS, especially midbrain, hypothalamus, limbic system, cerebellum, pineal gland, and spinal cord (Marieb and Hoen, 2007). It has been suggested that gut bacteria can play a crucial role in the production of serotonin (Reigstad et al., 2015; Hata et al., 2017). A study compared serotonin levels in germ-free mice to mice with gut microbes, and found that the germ-free mice produced significantly less serotonin (Yano et al., 2015). These results indicate that gut microbiota can be important determinants of enteric serotonin production and homeostasis.

Tryptophan is the metabolic precursor for serotonin, niacin (vitamin B-3) and picolinic acid and is needed for normal growth in infants and for nitrogen balance in adults. It is an essential amino acid, and must be obtained via food (Murray, 2013; United States Department of Health and Human Services, 2016). Tryptophan metabolism has shown to be reduced in patients with autism (Boccuto et al., 2013) and the commensal bacterium, Bifidobacteria infantis, which is a probiotic, has been shown to be involved in tryptophan metabolism in rat model (Desbonnet et al., 2008; Bravoa et al., 2011).

\section{Inflammation and the Gut-Brain Connection}

Besides serotonin, inflammation can influence the gut-brain axis. Inflammation is characterized by the production of proinflammatory cytokines such as tumor necrosis factor alpha (TNF- $\alpha)$. TNF- $\alpha$ levels are elevated in autism (Chez et al., 2007), and brains of autistic individuals display a pattern of elevated immune response, including activation of microglial cells, whose function is to eliminate pathogens and other threats (Gupta et al., 2014). Microglia are glial cells functioning as resident macrophages of the brain and the spinal cord, providing the primary active immune defense in the central nervous system (CNS).

Since $70-80 \%$ of human immune cells are located in gut-associated lymphoid tissue, lymphocyte accumulation and differentiation in the gastrointestinal tract can be triggered in response to changes in microbiota composition (Yamanaka et al., 2003; Douglas-Escobar et al., 2013). Mucosal surfaces of the intestinal tract are continuously exposed to both pathogenic and beneficial microorganisms, and these gut mucosal cells can trigger either pro- or anti-inflammatory responses. Gut epithelial 


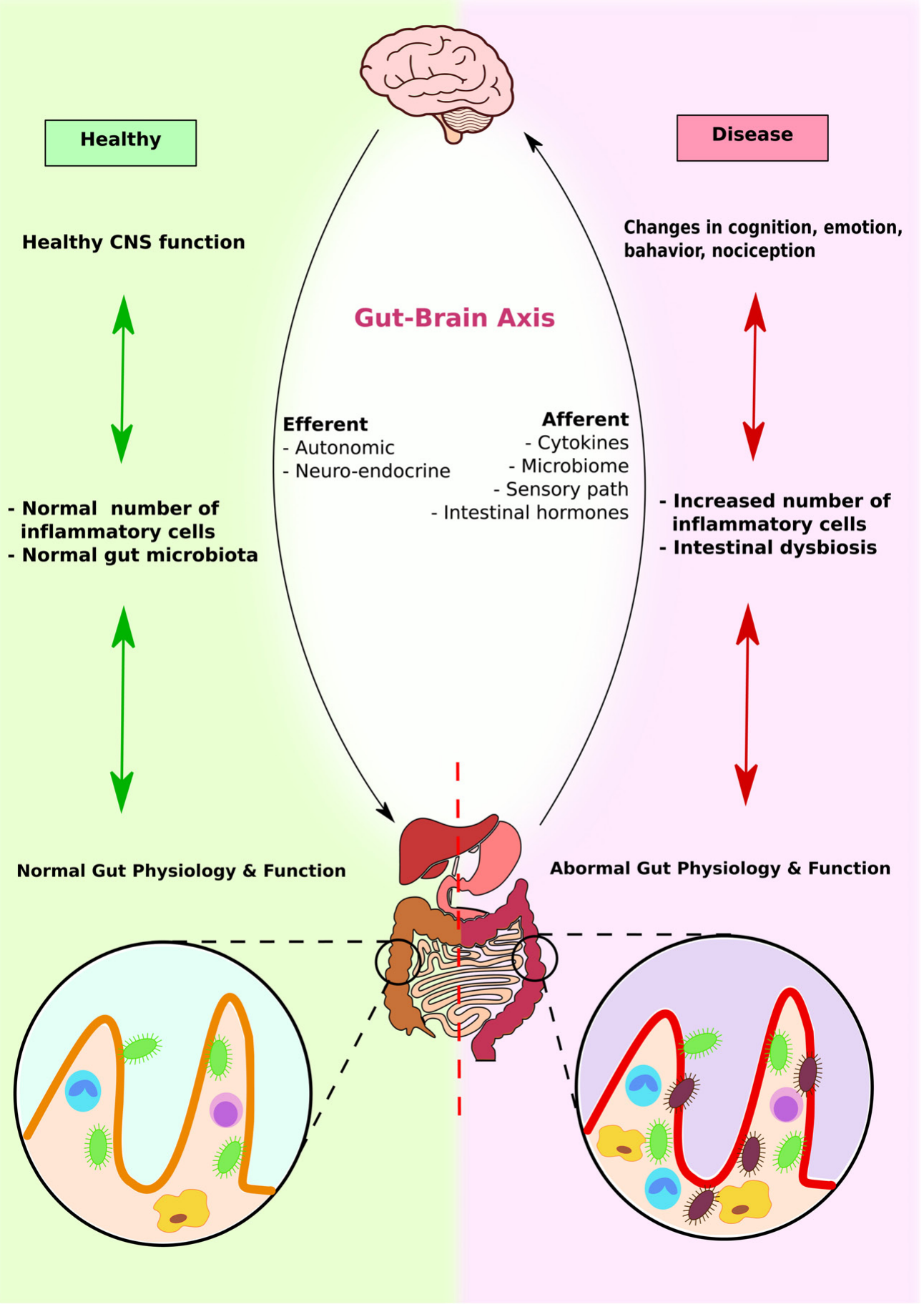

FIGURE 5 | Gut-brain axis and microbiota interplay. Brain, Gl system, and microbiota interact with each other to produce physiological responses. In healthy individuals, CNS function enhances normal immune response, which promotes colonization of normal gut microbiota and maximizes Gl function. In contrast, in diseased individuals, altered brain functions induce abnormal immune response and intestinal dysbiosis. This further contributes to abnormal gut physiology and function.

cells express toll-like receptors (TLRs) that can help identify and differentiate between beneficial and pathogenic bacteria, making them crucial for maintaining gut homeostasis (RakoffNahoum et al., 2004). Acute mucosal inflammation due to enteric bacterial pathogens can cause the chronic inflammatory response, but the events linking inflammatory activation in the gut to activation of glial cells and microglia in the brain requires further investigation. If inflammation in the gut lining causes gut 


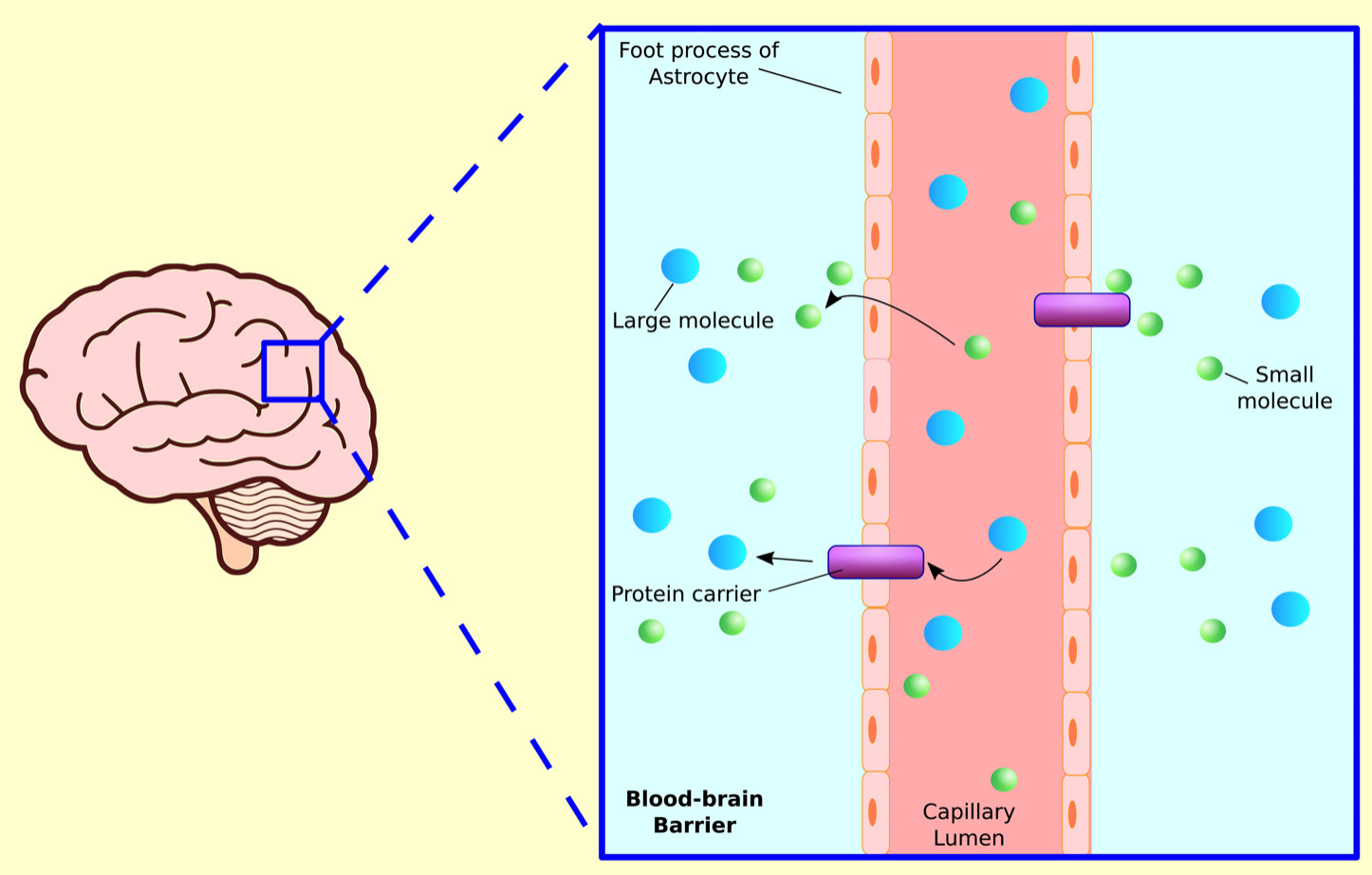

FIGURE 6 | Blood-brain barrier. Blood capillaries are surrounded by astrocyte processes, which enhance transcapillary molecular transport. Small molecules such as gasses or lipid soluble substances in capillary lumen can travel into tissue fluid via diffusion. Larger molecules such as glucose, amino acid, or other hydrophilic proteins are released from brain capillary into tissue via protein carriers.

permeability or leaky gut, pathogenic bacteria can escape through the gut lining into the bloodstream, and inflammatory cytokines traveling through the bloodstream can cause oxidative stress and promote systemic immune responses (Clayburgh et al., 2004).

\section{The Blood-Brain-Barrier}

Just as the gut has an epithelial lining that prevents pathogens from entering the blood stream, the brain also has a protective barrier to keep foreign invaders from entering the brain (Ballabh et al., 2004; Blanchette and Daneman, 2015). The blood-brain barrier $(\mathrm{BBB})$ is a layer of tightly packed endothelial cells that make up the walls of brain capillaries. The primary function of the $\mathrm{BBB}$ is to prevent free diffusion of substances from the blood into the brain and CSF. The passage across the membrane is selective, by means of lipid bilayer solubility and/or recognition by select transport molecules (Engelhardt and Sorokin, 2009) (Figure 6). Endothelial cells inhibit the diffusion of microscopic substances such as bacteria and large or hydrophilic molecules into the CSF, while allowing the diffusion of small hydrophobic molecules (Obermeier et al., 2016). Earlier it was believed that the BBB is very difficult to penetrate, even in a newborn, and that the brain is fiercely protected from bacteria and viruses. However, this notion is beginning to fade as the effects of inflammation on the BBB are better understood. It is now believed that the permeability properties of the $\mathrm{BBB}$ are not fixed, and inflammation is one of the important factors impacting the BBB permeability (de Wit et al., 2016). Induction of an inflammatory response in mice via LPS injection caused a long-term increase in BBB permeability (Stolp et al., 2009, 2011). Thus, an inflammatory insult during brain development can change BBB permeability and alter behavior in later life.

Gut microbes have been linked to altered BBB development and function during neurological disorders (Mirza and MaoDraayer, 2017), and a study in mice showed that gut microbes influence BBB penetrability (Bravoa et al., 2011). The development of the $\mathrm{BBB}$ between germ-free fetal mice and those with normal microbes was compared. It was observed that maternal gut microbes in late pregnancy can be neuroprotective and can influence BBB permeability in the offspring. Interestingly, the mice with normal microbes developed a strong BBB with tight junctions toward the late stages of fetal development, preventing entry of a tracer antibody. In fetuses whose mothers were germ-free, however, the antibody continued to enter the brain tissue, even late in pregnancy, demonstrating that stability of the BBB in the fetus depends upon the mother's microbial flora (Bravoa et al., 2011). 
Even after birth, the $\mathrm{BBB}$ is not a fixed entity and can still be influenced by gut microbes. When germ-free adult mice underwent fecal transplantation from animals with normal microbiomes, the junction proteins tightened, resulting in decreased BBB permeability (Saunders et al., 2012). These results suggest that dysbiosis in the GI tract can have adverse effects on BBB permeability.

\section{MITOCHONDRIA DYSFUNCTION AND ITS CONNECTION TO OXIDATIVE STRESS}

Besides normal functioning of the brain and intact BBB, the health of the cell depends on the proper functioning of mitochondria, which generate energy and adenosine triphosphate (ATP) (Kang et al., 2017). Mitochondria carry their own DNA, which codes for 37 proteins, 13 of which are subunits of oxidative phosphorylation which is crucial for the formation of ATP (Wang et al., 2004; Taylor and Turnbull, 2005). The ability of the mitochondria to generate energy is especially important for proper functioning of the central nervous system since brain cells require a lot of energy to communicate with each other. As a proof of this concept, mitochondrial dysfunction has been implicated in many neurological and psychiatric diseases, including neurodegenerative diseases (Verity et al., 2010; Frye and Rossignol, 2011; Ganguly et al., 2017; Gao et al., 2017; Smith et al., 2017). Clinical findings confirm that a significant subset of children with autism suffer from underlying mitochondrial dysfunction (Giulivi et al., 2010; Griffiths and Levy, 2017; Hollis et al., 2017). Mitochondria in granulocytes of children with autism consume far less oxygen than those of typically developing children, which is an indication of mitochondrial dysfunction (Napoli et al., 2014).

Mounting evidence shows that certain antibiotics can cause mitochondrial dysfunction. In addition to depleting the microbiota and altering immune function in the gut, antibiotics damage intestinal epithelium, a major insult to proper functioning in nutrient absorption and immune system regulation (Morgun et al., 2015). This study found that antibiotics and antibiotic-resistant microbes induced repression of genes coding for proteins constituting all five complexes of the mitochondrial respiratory chain. This significant finding was confirmed by another study where it was demonstrated that clinically relevant levels of antibiotics can cause mitochondrial dysfunction and lead to the production of detrimental reactive oxygen species (ROS) in mammalian cells. This was evident both in vitro and in vivo studies (Kalghatgi et al., 2013). ROS can directly interact with cellular components resulting in DNA, protein, and lipid damage. Several antibiotics, specifically tetracycline, minocycline, chloramphenicol and aminoglycosides are suspected to be "mito-toxic," because they inhibit mitochondrial DNA translation and protein synthesis (Balcells, 2016; Morén et al., 2016).

In mitochondrial dysfunction, cells cannot generate sufficient energy which ultimately can lead to apoptosis. The interconnectivity among mitochondrial dysfunction, oxidative stress and inflammation becomes evident, and all three are commonly observed in individuals with autism (Rossignol and Frye, 2014). In addition, environmental factors such as pesticides, cigarette smoke and radiation all can contribute to mitochondrial dysfunction (Kam and Banati, 2013; Meyer et al., 2013). The vulnerability of mitochondria to broad environmental toxins may be partially due to the fact that mitochondria have a negative potential and alkaline $\mathrm{pH}$ in the matrix, and that mitochondrial membranes have high lipid content, these properties make them accumulate cationic metals, amphiphilic organic chemicals and lipophilic compounds, leading to mitochondrial dysfunction and increased susceptibility to neurological diseases due to energy depletion.

\section{ENVIRONMENT AND THE EPIGENETIC CONNECTION IN AUTISM}

In addition to above discussed factors, the environment can play a crucial role in predisposition to ASD (Tran and Miyake, 2017; Waye and Cheng, 2018). The sharp rise in autism diagnosis in recent years leaves little doubt that autism cannot be purely genetic, however, we should examine the interactions between genes and the environment and particularly the role of epigenetics (Moosa et al., 2017; Siu and Weksberg, 2017; Eshraghi et al., 2018). Recognition of the role of the GI tract in cysteine absorption, and GSH production, and its influence over DNA and histone methylation, provides a novel perspective on how the microbiome and the use of antibiotics can exert effects on development, especially brain development.

Epigenetic regulation of gene expression is tied to chemical modifications (e.g., the addition of methyl groups) to DNA and to the histone proteins that associate tightly with DNA in the nucleus (Nardone et al., 2017; Roubroeks et al., 2017). These dynamic modifications can determine when or even if a given gene is expressed in a cell or organism. The science of epigenetics is gaining widespread attention as scientists are learning more about the complexities of how environment and lifestyle influences on DNA expression are bringing about epigenetic changes which can last a lifetime or even be transmitted across generations via germline cells (Wątroba et al., 2017; Virzì et al., 2018). Until recently, medical science primarily attributed disease to genetic determinism, but the more recent concept is introducing the causes for many diseases as epigenetic triggers, especially when certain diseases are more prevalent in specific areas or when the incidence of a disease dramatically increases.

There is a need to understand which environmental factors are combining with genetic susceptibility to increase autism prevalence. Genetics are unquestionably involved, however, genetic susceptibility and exposure to certain environmental insults that can trigger epigenetic changes provides a more reasonable understanding of autism (Waye and Cheng, 2018). An autism twin study concluded that there is considerable monozygotic (MZ) twin discordance, indicating a significant role for non-genetic factors (Wong et al., 2014). Since monozygotic twins share the same DNA sequence, differences in autism 
traits imply epigenetic involvement. Gene expression data in autism provide evidence for abnormalities in peripheral blood leukocytes that could represent a genetic and/or environmental predisposition to the disorder (Gregg et al., 2008).

It has been demonstrated that specific variants of the NOD2 gene that carry a high risk of developing IBD to their carriers are also associated with an altered intestinal microbiome (Naser et al., 2012). This study focused on the genes shaping the types of microbes that reside in the human gut, however, it would also be interesting to investigate if the human microbiome can alter gene expression, given that our microbial composition is more flexible and variable than our genes. Our diet has a profound impact and causes changes in our microbiome (David et al., 2014). Since the environment and food can alter the human microbiota, it is probable that there is a direct and complex interaction between human genes and microbiota, our second genome that needs to be explored in future investigations.

Transgenerational epigenetic effects are defined as effects on the phenotype (or on patterns of gene expression) that are detected across more than one generation and that cannot be explained by changes to the primary DNA sequence (Gröger et al., 2016; Pilling et al., 2017; Sharma, 2017). This includes epigenetic effects of environmental exposures on adults that alter the phenotype of the developing embryo via the placenta or the newborn via the milk (Daxinger and Whitelaw, 2012). A good example of transgenerational epigenetic consequences is BPA (bisphenol A) exposure that has shown to affect fertility in mice for three generations (Ziv-Gal et al., 2015). Pregnant mice exposed to low-dose BPA had significantly higher fertility and reproduction problems for three generations, as compared to the control group.

There is some compelling evidence that the microbial composition is directly responsible for triggering epigenetic changes. For example, a Japanese study showed that butyrate (a histone deacetylase inhibitor), a by-product of the digestion of dietary fiber by gut microbes, acts as an epigenetic switch that boosts the immune system by inducing production of regulatory $\mathrm{T}$ cells in the colon (Furusawa et al., 2013). One can hypothesize that changes in microbiota, especially in the early stages of life, could directly be responsible for turning on or off certain genes, in this case early use and overuse of antibiotics causing a shift in the microbial diversity and may be turning on the autism gene. Further studies are warranted to confirm this hypothesis that will shed light on the interconnection between epigenetics and alteration in gut microbiome.

\section{CONCLUSION AND FUTURE DIRECTIONS}

The microbiome is responsible for many functions that are impaired in autism such as metabolizing food, regulating the immune system, eliminating toxins and waste, absorbing nutrients, producing neurotransmitters, preventing the colonization of the gut by pathogenic bacteria, and maintaining the tight junctions of intestinal epithelial cells. Microbial constitution and development in early childhood has been shown to affect the blood-brain barrier permeability. Early use and over-use of antibiotics can lead to an imbalance between beneficial microbes and pathogenic microbes, which can in turn lead to inflammation, immune dysregulation, allergies, diabetes, metabolic problems, yeast overgrowth, and gastrointestinal complications. Not surprisingly, all of these pathologies display an increased incidence in children with autism. Although GI complications have been associated with ASD, the precise prevalence of these complications is still not known. The reported estimates of GI symptoms in ASD subjects vary widely from 9-91\% (Buie et al., 2010; Fulceri et al., 2016). These very large variations can be attributed to small sample size, different methodological approaches (e.g., data source and time period for reporting), different study populations and lack of consensus in the clinicians regarding GI symptomology. Further studies using large cohorts and consensus in clinicians about GI symptomology is warranted in order to precisely estimate the prevalence of GI complications in ASD subjects and how it can contribute to the development of autism.

In addition to GI symptoms, there has been a significant discrepancy regarding altered gut microbiota composition in ASD patients compared to neurotypical subjects. This discrepancy may be due to differences in technologies used to determine microbial composition, geographical differences between participants (which may result in genetic and/or dietary differences), potential sub-types of gut microbiota within ASD groups, small sample size and inadequate statistical control for testing multiple-hypotheses. Studies using large sample sizes from the same geographical area and robust statistical analysis of the data will help in addressing some of these issues. In addition, emerging technologies that involve characterizing metabolomics profiles that can be correlated with gut microbial structure and interrelated functional pathways will provide valuable information to understand the role of the gut microbiota in autism.

Besides GI complications, brain inflammation is a hallmark comorbid pathology observed in autism. Longitudinal studies of brain inflammation compared to gut inflammation and microbial imbalance needs to be performed. The inflammatory insults during the developmental stages of brain maturation can affect blood-brain barrier permeability and may lead to encephalitis. Furthermore, epigenetic dysregulation is an important consideration in the etiology of autism, reflecting the impact of food, drugs and the environment on the intestinal microbiome. Alteration of the intestinal microbiome can lead to altered genetic expression and potentially contribute to autism causation.

Through the many pathways elucidated above, the microbiome of the human gut can be seen to play an important role in the etiology of autism. This field shows promise for understanding the true pathogenesis of this increasingly prevalent disease. A deeper understanding about gut-brain axis underlying pathogenesis of autism and how alteration in gut microbiota leads to oxidative stress in ASD patients will open up novel avenues for the management, screening and prophylaxis of autism as well developing novel treatment modalities for ASD. 


\section{AUTHOR CONTRIBUTIONS}

All authors listed have made a substantial, direct and intellectual contribution to the work, and approved it for publication.

\section{REFERENCES}

Adams, D. J., Susi, A., Erdie-Lalena, C. R., Gorman, G., Hisle-Gorman, E., Rajnik, M., et al. (2016). Otitis media and related complications among children with autism spectrum disorders. J. Autism Dev. Disord. 46, 1636-1642. doi: 10.1007/s10803-015-2689-x

Adams, J. B., Johansen, L. J., Powell, L. D., Quig, D., and Rubin, R. A. (2011). Gastrointestinal flora and gastrointestinal status in children with autismcomparisons to typical children and correlation with autism severity. BMC Gastroenterol. 11:22. doi: 10.1186/1471-230X-11-22

Aoyama, K., and Nakaki, T. (2013). Neuroprotective properties of the excitatory amino acid carrier 1 (EAAC1). Amino Acids 45, 133-142. doi: 10.1007/s00726013-1481-5

Aoyama, K., and Nakaki, T. (2015). Glutathione in cellular redox homeostasis: association with the excitatory amino acid carrier 1 (EAAC1). Molecules 20, 8742-8758. doi: 10.3390/molecules20058742

Arrieta, M. C., Stiemsma, L. T., Amenyogbe, N., Brown, E. M., and Finlay, B. (2014). The intestinal microbiome in early life: health and disease. Front. Immunol. 5:427. doi: 10.3389/fimmu.2014.00427

Ashwood, P., Anthony, A., Pellicer, A. A., Torrente, F., Walker-Smith, J. A., and Wakefield, A. J. (2003). Intestinal lymphocyte populations in children with regressive autism: evidence for extensive mucosal immunopathology. J. Clin. Immunol. 23, 504-517. doi: 10.1023/B:JOCI.0000010427.05143.bb

Athanasopoulos, D., Karagiannis, G., and Tsolaki, M. (2016). Recent findings in Alzheimer disease and nutrition focusing on epigenetics. Adv. Nutr. 7, 917-927. doi: 10.3945/an.116.012229

Awasthi, Y. C., Ramana, K. V., Chaudhary, P., Srivastava, S. K., and Awasthi, S. (2017). Regulatory roles of glutathione-S-transferases and 4-hydroxynonenal in stress-mediated signaling and toxicity. Free Radic. Biol. Med. 111, 235-243. doi: 10.1016/j.freeradbiomed.2016.10.493

Ayme-Dietrich, E., Aubertin-Kirch, G., Maroteaux, L., and Monassier, L. (2017). Cardiovascular remodeling and the peripheral serotonergic system. Arch. Cardiovasc. Dis. 110, 51-59. doi: 10.1016/j.acvd.2016.08.002

Balcells, C. (2016). Mitochondrial Toxicity | Mitochondrial Disease Action Committee - MitoAction. Available at: http://www.mitoaction.org/blog/ medication-exposures-mitochondrial-toxicity [accessed 21 December, 2016].

Ballabh, P., Braun, A., and Nedergaard, M. (2004). The blood-brain barrier: an overview: structure, regulation, and clinical implications. Neurobiol. Dis. 16, 1-13. doi: 10.1016/j.nbd.2003.12.016

Bauman, M. D., Iosif, A. M., Smith, S. E., Bregere, C., Amaral, D. G., and Patterson, P. H. (2014). Activation of the maternal immune system during pregnancy alters behavioral development of rhesus monkey offspring. Biol. Psychiatry 75, 332-341. doi: 10.1016/j.biopsych.2013.06.025

Berk, M., Kapczinski, F., Andreazza, A. C., Dean, O. M., Giorlando, F., Maes, M., et al. (2011). Pathways underlying neuroprogression in bipolar disorder: focus on inflammation, oxidative stress and neurotrophic factors. Neurosci. Biobehav. Rev. 35, 804-817. doi: 10.1016/j.neubiorev.2010.10.001

Biasucci, G., Benenati, B., Morelli, L., Bessi, E., and Boehm, G. (2008). Cesarean delivery may affect the early biodiversity of intestinal bacteria. J. Nutr. 138, 1796S-1800S. doi: 10.1093/jn/138.9.1796S

Biasucci, G., Rubini, M., Riboni, S., Morelli, L., Bessi, E., and Retetangos, C. (2010). Mode of delivery affects the bacterial community in the newborn gut. Early Hum. Dev. 86, 13-15. doi: 10.1016/j.earlhumdev.2010.01.004

Bilbo, S. D., Block, C. L., Bolton, J. L., Hanamsagar, R., and Tran, P. K. (2017). Beyond infection - maternal immune activation by environmental factors, microglial development, and relevance for autism spectrum disorders. Exp. Neurol. 299, 241-251. doi: 10.1016/j.expneurol.2017.07.002

Bjørn-Yoshimoto, W. E., and Underhill, S. M. (2016). The importance of the excitatory amino acid transporter 3 (EAAT3). Neurochem. Int. 98, 4-18. doi: 10.1016/j.neuint.2016.05.007

\section{ACKNOWLEDGMENTS}

We are thankful to Keith Bell for assistance in this manuscript, and April Mann for the critical reading of the manuscript.

Blanchard, D. C., and Meyza, K. (2017). Risk assessment and serotonin: animal models and human psychopathologies. Behav. Brain Res. doi: 10.1016/j.bbr. 2017.07.008 [Epub ahead of print].

Blanchette, M., and Daneman, R. (2015). Formation and maintenance of the BBB. Mech. Dev. 138, 8-16. doi: 10.1016/j.mod.2015.07.007

Blaser, M. (2014). Missing Microbes: How the Overuse of Antibiotics is Fueling our Modern Plagues. New York, NY: Henry Holt and Company, LLC.

Boccuto, L., Chen, C. F., Pittman, A. R., Skinner, C. D., McCartney, H. J., Jones, K., et al. (2013). Decreased tryptophan metabolism in patients with autism spectrum disorders. Mol. Autism 4:16. doi: 10.1186/2040-2392-4-16

Bonfili, L., Cecarini, V., Cuccioloni, M., Angeletti, M., Berardi, S., Scarpona, S., et al. (2018). SLAB51 probiotic formulation activates SIRT1 pathway promoting antioxidant and neuroprotective effects in an AD mouse model. Mol. Neurobiol. doi: 10.1007/s12035-018-0973-4 [Epub ahead of print].

Bravoa, J. A., Forsythe, P., Chew, M. V., Escaravage, E., Savignac, H. M., Dinan, T. G., et al. (2011). Ingestion of Lactobacillus strain regulates emotional behavior and central GABA receptor expression in a mouse via the vagus nerve. Proc. Natl. Acad. Sci. U.S.A. 108, 16050-16055. doi: 10.1073/pnas.1102 999108

Brodin, P., Jojic, V., Gao, T., Bhattacharya, S., Angel, C. J., Furman, D., et al. (2015). Variation in the human immune system is largely driven by non-heritable influences. Cell 160, 37-47. doi: 10.1016/j.cell.2014.12.020

Brummelte, S., Mc Glanaghy, E., Bonnin, A., and Oberlander, T. F. (2017). Developmental changes in serotonin signaling: implications for early brain function, behavior and adaptation. Neuroscience 7, 212-231. doi: 10.1016/j. neuroscience.2016.02.037

Buffie, C. G., Jarchum, I., Equinda, M., Lipuma, L., Gobourne, A., Viale, A., et al. (2012). Profound alterations of intestinal microbiota following a single dose of clindamycin results in sustained susceptibility to Clostridium difficile-induced colitis. Infect. Immun. 80, 62-73. doi: 10.1128/IAI.05496-11

Buie, T., Campbell, D. B., Fuchs, G. J. III, Furuta, G. T., Levy, J., Vandewater, J., et al. (2010). Evaluation, diagnosis, and treatment of gastrointestinal disorders in individuals with ASDs: a consensus report. Pediatrics 125(Suppl. 1), S1-S18. doi: 10.1542 /peds.2009-1878C

Buscarinu, M. C., Romano, S., Mechelli, R., Pizzolato Umeton, R., Ferraldeschi, M., Fornasiero, A., et al. (2018). Intestinal permeability in relapsing-remitting multiple sclerosis. Neurotherapeutics 15, 68-74. doi: 10.1007/s13311-0170582-3

Cabrera-Rubio, R., Collado, M. C., Laitinen, K., Salminen, S., Isolauri, E., and Mira, A. (2012). The human milk microbiome changes over lactation and is shaped by maternal weight and mode of delivery. Am. J. Clin. Nutr. 96, 544-551. doi: 10.3945/ajcn.112.037382

Centers for Disease Control and Prevention [CDC] (2006). Community-associated methicillin-resistant Staphylococcus aureus infection among healthy newborns: Chicago and Los Angeles County, 2004. MMWR Morb. Mortal. Wkly. Rep. 55, 329-332.

Centers for Disease Control and Prevention [CDC] (2014). National Vital Statistics Reports. Primary Cesarean Delivery Rates, by State: Results from the Revised Birth Certificate, 2006-2012. Available at: https://www.cdc.gov/nchs/fastats/ delivery.htm

Chai, G., Governale, L., McMahon, A. W., Trinidad, J. P., Staffa, J., and Murphy, D. (2012). Trends of outpatient prescription drug utilization in US children, 2002-2010. Pediatrics 130, 23-31. doi: 10.1542/peds.2011-2879

Chaidez, V., Hansen, R. L., and Hertz-Picciotto, I. (2014). Gastrointestinal problems in children with autism, developmental delays or typical development. J. Autism Dev. Dis. 44, 1117-1127. doi: 10.1007/s10803013-1973-x

Chédotal, A., and Richards, L. J. (2010). Wiring the brain: the biology of neuronal guidance. Cold Spring Harb. Perspect. Biol. 2:a001917. doi: 10.1101/cshperspect. a001917 
Chen, D., Meng, L., Pei, F., Zheng, Y., and Leng, J. (2017). A review of DNA methylation in depression. J. Clin. Neurosci. 43, 39-46. doi: 10.1016/j.jocn.2017. 05.022

Chez, M. G., Dowling, T., Patel, P. B., Khanna, P., and Kominsky, M. (2007). Elevation of tumor necrosis factor-alpha in cerebrospinal fluid of autistic children. Pediatr. Neurol. 36, 361-365. doi: 10.1016/j.pediatrneurol.2007.01.012

Chu, D. M., Meyer, K. M., Prince, A. L., and Aagaard, K. M. (2016). Impact of maternal nutrition in pregnancy and lactation on offspring gut microbial composition and function. Gut Microbes 7, 459-470. doi: 10.1080/19490976. 2016.1241357

Clayburgh, D. R., Shen, L., and Turner, J. R. (2004). A porous defense: the leaky epithelial barrier in intestinal disease. Lab. Invest. 84, 282-291. doi: 10.1038/ labinvest. 3700050

Cohly, H. H. P., and Panja, A. (2005). Immunological findings in autism. Int. Rev. Neurobiol. 71, 317-341. doi: 10.1016/S0074-7742(05)71013-8

Collado, M. C., Rautava, S., Aakko, J., Isolauri, E., and Salminen, S. (2016). Human gut colonisation may be initiated in utero by distinct microbial communities in the placenta and amniotic fluid. Sci. Rep. 6:23129. doi: 10.1038/srep23129

Coretti, L., Cristiano, C., Florio, E., Scala, G., Lama, A., Keller, S., et al. (2017). Sexrelated alterations of gut microbiota composition in the BTBR mouse model of autism spectrum disorder. Sci. Rep. 7:45356. doi: 10.1038/srep45356

Crott, J. W. (2017). Effects of altered parental folate and one-carbon nutrient status on offspring growth and metabolism. Mol. Aspects Med. 53, 28-35. doi: 10.1016/j.mam.2016.11.001

David, L. A., Maurice, C. F., Carmody, R. N., Gootenberg, D. B., Button, J. E., Wolfe, B. E., et al. (2014). Diet rapidly and reproducibly alters the human gut microbiome. Nature 505, 559-563. doi: 10.1038/nature12820

Daxinger, L., and Whitelaw, E. (2012). Understanding transgenerational epigenetic inheritance via the gametes in mammals. Nat. Rev. Genet. 13, 153-162. doi: $10.1038 / \mathrm{nrg} 3188$

De Angelis, M., Piccolo, M., Vannini, L., Siragusa, S., De Giacomo, A., Serrazzanetti, D. I., et al. (2013). Fecal microbiota and metabolome of children with autism and pervasive developmental disorder not otherwise specified. PLoS One 8:e76993. doi: 10.1371/journal.pone.0076993

de la Fuente-Nunez, C., Meneguetti, B. T., Franco, O. L., and Lu, T. K. (2018). Neuromicrobiology: how microbes influence the brain. ACS Chem. Neurosci. 9, 141-150. doi: 10.1021/acschemneuro.7b00373

de Magistris, L., Familiari, V., Pascotto, A., Sapone, A., Frolli, A., Iardino, P., et al. (2010). Alterations of the intestinal barrier in patients with autism spectrum disorders and in their first-degree relatives. J. Pediatr. Gastroentreol. Nutr. 51, 418-424. doi: 10.1097/MPG.0b013e3181dcc4a5

de Wit, N. M., Vanmol, J., Kamermans, A., Hendriks, J., and de Vries, H. E. (2016). Inflammation at the blood-brain barrier: the role of liver X receptors. Neurobiol. Dis. 107, 57-65. doi: 10.1016/j.nbd.2016.09.015

Degnan, P. H., Barry, N. A., Mok, K. C., Taga, M. E., and Goodman, A. L. (2014). Human gut microbes use multiple transporters to distinguish vitamin B12 analogs and compete in the gut. Cell Host Microb 15, 47-57. doi: 10.1016/j. chom.2013.12.007

Desbonnet, L., Garrett, L., Clarke, G., Bienenstock, J., and Dinan, T. G. (2008). The probiotic Bifidobacteria infantis: an assessment of potential antidepressant properties in the rat. J. Psychiatr. Res. 43, 164-174. doi: 10.1016/j.jpsychires. 2008.03.009

Dethlefsen, L., Huse, S., Sogin, M. L., and Relman, D. A. (2008). The pervasive effects of an antibiotic on the human gut microbiota, as revealed by deep 16S rRNA sequencing. PLoS Biol. 6:e280. doi: 10.1371/journal.pbio. 0060280

D’Eufemia, P., Celli, M., Finocchiaro, R., Pacifico, L., Viozzi, L., Zaccagnini, M., et al. (1996). Abnormal intestinal permeability in children with autism. Acta Paediatr. 85, 1076-1079. doi: 10.1111/j.1651-2227.1996.tb14220.x

DeVilbiss, E. A., Gardner, R. M., Newschaffer, C. J., and Lee, B. K. (2015). Maternal folate status as a risk factor for autism spectrum disorders: a review of existing evidence. Br. J. Nutr. 114, 663-672. doi: 10.1017/S0007114515002470

Douglas-Escobar, M., Elliott, E., and Neu, J. (2013). Effect of intestinal microbial ecology on the developing brain. JAMA Pediatr. 167, 374-379. doi: 10.1001/ jamapediatrics.2013.497

Edmiston, E., Ashwood, P., and Van de Water, J. (2017). Autoimmunity, autoantibodies, and autism spectrum disorder. Biol. Psychiatry 81, 383-390. doi: 10.1016/j.biopsych.2016.08.031
El-Ansary, A., Bjørklund, G., Chirumbolo, S., and Alnakhli, O. M. (2017). Predictive value of selected biomarkers related to metabolism and oxidative stress in children with autism spectrum disorder. Metab. Brain Dis. 32, 1209-1221. doi: 10.1007/s11011-017-0029-x

Elliott, H. R., Samuels, D. C., Eden, J. A., Relton, C. L., and Chinnery, P. F. (2008). Pathogenic mitochondrial DNA mutations are common in the general population. Am. J. Hum. Genet. 83, 254-260. doi: 10.1016/j.ajhg.2008.07.004

Engelhardt, B., and Sorokin, L. (2009). The blood-brain and the bloodcerebrospinal fluid barriers: function and dysfunction. Semin. Immunopathol. 31, 497-511. doi: 10.1007/s00281-009-0177-0

Eshraghi, A., Liu, G., Kay, S., Eshraghi, S., Mittal, J., Moshiree, B., et al. (2018). Epigenetics and autism spectrum disorder: is there a correlation? Front. Cell. Neurosci. 12:78. doi: 10.3389/fncel.2018.00078

Filiano, A. J., Gadani, S. P., and Kipnis, J. (2015). Interactions of innate and adaptive immunity in brain development and function. Brain Res. 1617, 18-27. doi: 10.1016/j.brainres.2014.07.050

Finegold, S. M. (2011). Desulfovibrio species are potentially important in regressive autism. Med. Hypotheses 77, 270-274. doi: 10.1016/j.mehy.2011.04.032

Finegold, S. M., Dowd, S. E., Gontcharova, V., Liu, C., Henley, K. E., Wolcott, R. D., et al. (2010). Pyrosequencing study of fecal microflora of autistic and control children. Anaerobe 16, 444-453. doi: 10.1016/j.anaerobe.2010. 06.008

Finegold, S. M., Molitoris, D., Song, Y., Liu, C., Vaisanen, M. L., Bolte, E., et al. (2002). Gastrointestinal microflora studies in late-onset autism. Clin. Infect. Dis. 35, S6-S16. doi: 10.1086/341914

Fluegge, K. (2017). Humoral immunity and autism spectrum disorders. Immunol. Lett. 185, 90-92. doi: 10.1016/j.imlet.2017.03.003

Frustaci, A., Neri, M., Cesario, A., Adams, J. B., Domenici, E., Dalla Bernardina, B., et al. (2012). Oxidative stress-related biomarkers in autism: systematic review and meta-analyses. Free Radic. Biol. Med. 52, 2128-2141. doi: 10.1016/j. freeradbiomed.2012.03.011

Frye, R. E., and Rossignol, D. A. (2011). Mitochondrial dysfunction can connect the diverse medical symptoms associated with autism spectrum disorders. Pediatr. Res. 69, 41R-47R. doi: 10.1203/PDR.0b013e318212f16b

Fulceri, F., Morelli, M., Santocchi, E., Cena, H., Del Bianco, T., Narzisi, A., et al. (2016). Gastrointestinal symptoms and behavioral problems in preschoolers with Autism Spectrum Disorder. Dig. Liver Dis. 48, 248-254. doi: 10.1016/j.dld. 2015.11.026

Furusawa, Y., Obata, Y., Fukuda, S., Endo, T. A., Nakato, G., Takahashi, D., et al. (2013). Commensal microbe-derived butyrate induces the differentiation of colonic regulatory T cells. Nature 504, 446-450. doi: 10.1038/nature 12721

Ganguly, G., Chakrabarti, S., Chatterjee, U., and Saso, L. (2017). Proteinopathy, oxidative stress and mitochondrial dysfunction: cross talk in Alzheimer's disease and Parkinson's disease. Drug Des. Devel. Ther. 16, 797-810. doi: 10.2147/ DDDT.S130514

Gao, J., Wang, L., Liu, J., Xie, F., Su, B., and Wang, X. (2017). Abnormalities of mitochondrial dynamics in neurodegenerative diseases. Antioxidants 6:E25. doi: $10.3390 /$ antiox 6020025

García-Giménez, J. L., Romá-Mateo, C., Pérez-Machado, G., Peiró-Chova, L., and Pallardó, F. V. (2017). Role of glutathione in the regulation of epigenetic mechanisms in disease. Free Radic. Biol. Med. 112, 36-48. doi: 10.1016/j. freeradbiomed.2017.07.008

Gasparini, C. F., Smith, R. A., and Griffiths, L. R. (2017). Genetic and biochemical changes of the serotonergic system in migraine pathobiology. J. Headache Pain 18:20. doi: 10.1186/s10194-016-0711-0

Ghanizadeh, A., Akhondzadeh, S., Hormozi, M., Makarem, A., AbotorabiZarchi, M., and Firoozabadi, A. (2012). Glutathione-related factors and oxidative stress in autism, a review. Curr. Med. Chem. 19, 4000-4005. doi: 10.2174/092986712802002572

Gibiino, G., Ianiro, G., Cammarota, G., and Gasbarrini, A. (2017). The gut microbiota: its anatomy and physiology during all life. Minerva Gastroenterol. Dietol. 63, 329-336.

Giulivi, C., Zhang, Y., Omanska-Klusek, A., Ross-Inta, C., Wong, S., HertzPicciotto, I., et al. (2010). Mitochondrial dysfunction in autism. JAMA 304, 2389-2396. doi: 10.1001/jama.2010.1706

Godhia, M., and Patel, N. (2013). Colostrum - its composition, benefits as a nutraceutical. Curr. Res. Nutr. Food Sci. 1, 37-47. doi: 10.12944/CRNFSJ.1.1.04 
Goines, P., and Van de Water, J. (2010). The Immune system's role in the biology of autism. Curr. Opin. Neurol. 23, 111-117. doi: 10.1097/WCO.0b013e3283373514

Gondalia, S. V., Palombo, E. A., Knowles, S. R., Cox, S. B., Meyer, D., and Austin, D. W. (2012). Molecular characterisation of gastrointestinal microbiota of children with autism (with and without gastrointestinal dysfunction) and their neurotypical siblings. Autism Res. 5, 419-427. doi: 10.1002/aur.1253

Gregg, J. P., Lit, L., Baron, C. A., Hertz-Picciotto, I., Walker, W., Davis, R. A., et al. (2008). Gene expression changes in children with autism. Genomics 91, 22-29. doi: 10.1016/j.ygeno.2007.09.003

Gregory, K. E., Samuel, B. S., Houghteling, P., Shan, G., Ausubel, F. M., Sadreyev, R. I., et al. (2016). Influence of maternal breast milk ingestion on acquisition of the intestinal microbiome in preterm infants. Microbiome 4:68. doi: 10.1186/ s40168-016-0214-x

Griffiths, K. K., and Levy, R. J. (2017). Evidence of mitochondrial dysfunction in autism: biochemical links, genetic-based associations, and non-energyrelated mechanisms. Oxid. Med. Cell. Longev. 2017:4314025. doi: 10.1155/2017/ 4314025

Gröger, N., Matas, E., Gos, T., Lesse, A., Poeggel, G., Braun, K., et al. (2016). The transgenerational transmission of childhood adversity: behavioral, cellular, and epigenetic correlates. J. Neural Transm. 123, 1037-1052. doi: 10.1007/s00702016-1570-1

Grönlund, M. M., Lehtonen, O. P., and Eerola, E. (1999). Fecal microflora in healthy infants born by different methods of delivery: permanent changes in intestinal flora after cesarean delivery. J. Pediatr. Gastroenterol. Nutr. 28, 19-25. doi: 10.1097/00005176-199901000-00007

Gu, F., Chauhan, V., and Chauhan, A. (2015). Glutathione redox imbalance in brain disorders. Curr. Opin. Clin. Nutr. Metab. Carem. 18, 89-95. doi: 10.1097/ MCO.0000000000000134

Gupta, S., Ellis, S. E., Ashar, F. N., Moes, A., Bader, J. S., Zhan, J., et al. (2014). Transcriptome analysis reveals dysregulation of innate immune response genes and neuronal activity-dependent genes in autism. Nat. Commun. 5:5748. doi: $10.1038 /$ ncomms6748

Gyuraszova, M., Kovalcikova, A., and Gardlik, R. (2017). Association between oxidative status and the composition of intestinal microbiota along the gastrointestinal tract. Med. Hypotheses 103, 81-85. doi: 10.1016/j.mehy.2017. 04.011

Hata, T., Asano, Y., Yoshihara, K., Kimura-Todani, T., Miyata, N., Zhang, X. T., et al. (2017). Regulation of gut luminal serotonin by commensal microbiota in mice. PLoS One 12:e0180745. doi: 10.1371/journal.pone. 0180745

Hedrich, C. M. (2017). Epigenetics in SLE. Curr. Rheumatol. Rep. 19:58. doi: 10. 1007/s11926-017-0685-1

Herrmann, W., Schorr, H., Purschwitz, K., Rassoul, F., and Richter, V. (2001). Total homocysteine, vitamin B(12), and total antioxidant status in vegetarians. Clin. Chem. 47, 1094-1101.

Hevia, A., Milani, C., López, P., Cuervo, A., Arboleya, S., Duranti, S., et al. (2014). Intestinal dysbiosis associated with systemic lupus erythematosus. mBio 5:e1548-14. doi: 10.1128/mBio.01548-14

Holingue, C., Newill, C., Lee, L. C., Pasricha, P. J., and Daniele Fallin, M. (2018). Gastrointestinal symptoms in autism spectrum disorder: a review of the literature on ascertainment and prevalence. Autism Res. 11, 24-36. doi: 10.1002/aur. 1854

Hollis, F., Kanellopoulos, A. K., and Bagni, C. (2017). Mitochondrial dysfunction in Autism Spectrum Disorder: clinical features and perspectives. Curr. Opin. Neurobiol. 16, 178-187. doi: 10.1016/j.conb.2017.05.018

Howsmon, D. P., Kruger, U., Melnyk, S., James, S. J., and Hahn, J. (2017). Classification and adaptive behavior prediction of children with autism spectrum disorder based upon multivariate data analysis of markers of oxidative stress and DNA methylation. PLoS. Comput. Biol. 13:e1005385. doi: 10.1371/ journal.pcbi.1005385

Hsiao, E. Y. (2014). Gastrointestinal issues in autism spectrum disorder. Harv. Rev. Psychiatry 22, 104-111. doi: 10.1097/HRP.0000000000000029

Hsiao, E. Y., McBride, S. W., Hsien, S., Sharon, G., Hyde, E. R., McCue, T., et al. (2013). Microbiota modulate behavioral and physiological abnormalities associated with neurodevelopmental disorders. Cell 155, 1451-1463. doi: 10. 1016/j.cell.2013.11.024

Huurre, A., Kalliomäki, M., Rautava, S., Rinne, M., Salminen, S., and Isolauri, E. (2008). Mode of delivery - effects on gut microbiota and humoral immunity. Neonatology 93, 236-240. doi: 10.1159/000111102
Isaksson, J., Pettersson, E., Kostrzewa, E., Diaz Heijtz, R., and Bölte, S. (2017). Brief Report: association between autism spectrum disorder, gastrointestinal problems and perinatal risk factors within sibling pairs. J. Autism Dev. Disord. 47, 2621-2627. doi: 10.1007/s10803-017-3169-2

Iwanaga, T., Goto, M., and Watanabe, M. (2005). Cellular distribution of glutamate transporters in the gastrointestinal tract of mice: an immunohistochemical and in situ hybridization approach. Biomed. Res. 26, 271-278. doi: 10.2220/ biomedres.26.271

James, S. J., Cutler, P., Melnyk, S., Jernigan, S., Janak, L., Gaylor, D. W., et al. (2004). Metabolic biomarkers of increased oxidative stress and impaired methylation capacity in children with autism. Am. J. Clin. Nutr. 80, 1611-1617. doi: 10.1093/ ajcn/80.6.1611

Jernberg, C., Löfmark, S., and Edlund, C. (2007). Long-term ecological impacts of antibiotic administration on the human intestinal microbiota. ISME J. 1, 56-66. doi: 10.1038/ismej.2007.3

Jernberg, C., Löfmark, S., and Edlund, C. (2010). Long-term impacts of antibiotic exposure on the human intestinal microbiota. Microbiology 156, 3216-3223. doi: 10.1099/mic.0.040618-0

Jost, T., Lacroix, C., Braegger, C., and Chassard, C. (2013). Assessment of bacterial diversity in breast milk using culture-dependent and culture-independent approaches. Br. J. Nutr. 110, 1253-1262. doi: 10.1017/S0007114513000597

Jost, T., Lacroix, C., Braegger, C. P., Rochat, F., and Chassard, C. (2014). Vertical mother-neonate transfer of maternal gut bacteria via breastfeeding. Environ. Microbiol. 16, 2891-2904. doi: 10.1111/1462-2920.12238

Kalghatgi, S., Spina, C. S., Costello, J. C., Liesa, M., Morones-Ramirez, J. R., Slomovic, S., et al. (2013). Bactericidal antibiotics induce mitochondrial dysfunction and oxidative damage in mammalian cells. Sci. Transl. Med. 5:192ra85. doi: 10.1126/scitranslmed.3006055

Kam, W. W., and Banati, R. B. (2013). The effects of ionizing radiation on mitochondria. Free Radic. Biol. Med. 65, 607-619. doi: 10.1016/j.freeradbiomed. 2013.07.024

Kang, D. W., Ilhan, Z. E., Isern, N. G., Hoyt, D. W., Howsmon, D. P., Shaffer, M., et al. (2018). Differences in fecal microbial metabolites and microbiota of children with autism spectrum disorders. Anaerobe 49, 121-131. doi: 10.1016/j. anaerobe.2017.12.007

Kang, D. W., Park, J. G., Ilhan, Z. E., Wallstrom, G., Labaer, J., Adams, J. B., et al. (2013). Reduced incidence of Prevotella and other fermenters in intestinal microflora of autistic children. PLoS One 8:e68322. doi: 10.1371/journal.pone. 0068322

Kang, Y., Fielden, L. F., and Stojanovski, D. (2017). Mitochondrial protein transport in health and disease. Semin. Cell. Dev. Biol. 76, 142-153. doi: 10.1016/ j.semcdb.2017.07.028

Kim, N., Yun, M., Oh, Y. J., and Choi, H. J. (2018). Mind-altering with the gut: modulation of the gut-brain axis with probiotics. J. Microbiol. 56, 172-182. doi: 10.1007/s12275-018-8032-4

Kohane, I. S., McMurry, A., Weber, G., MacFadden, D., Rappaport, L., Kunkel, L., et al. (2012). The co-morbidity burden of children and young adults with autism spectrum disorders. PLoS One 7:e33224. doi: 10.1371/journal.pone.00 33224

Krejcova, L., Richtera, L., Hynek, D., Labuda, J., and Adam, V. (2017). Current trends in electrochemical sensing and biosensing of DNA methylation. Biosens. Bioelectron. 97, 384-399. doi: 10.1016/j.bios.2017.06.004

Kushak, R. I., Buie, T. M., Murray, K. F., Newburg, D. S., Chen, C., Nestoridi, E., et al. (2016). Evaluation of intestinal function in children with autism and gastrointestinal symptoms. J. Pediatr. Gastroenterol. Nutr. 62, 687-691. doi: 10.1097/MPG.0000000000001174

Lau, K., Srivatsav, V., Rizwan, A., Nashed, A., Liu, R., Shen, R., et al. (2017). Bridging the gap between gut microbial dysbiosis and cardiovascular diseases. Nutrients 9:E859. doi: 10.3390/nu9080859

Leung, A. K., and Wong, A. H. C. (2017). Acute otitis media in children. Recent Pat. Inflamm. Allergy Drug Discov. 11, 32-40. doi: 10.2174/ 1874609810666170712145332

Li, X., Chauhn, A., Sheikh, A. M., Patil, S., Chauhan, V., Li, X. M., et al. (2009). Elevated immune response in the brain of autistic patients. J. Neurol. 207, 111-116. doi: 10.1016/j.jneuroim.2008.12.002

Liu, X., Zou, Q., Zeng, B., Fang, Y., and Wei, H. (2013). Analysis of fecal Lactobacillus community structure in patients with early rheumatoid arthritis. Curr. Microbiol. 67, 170-176. doi: 10.1007/s00284-013-0338-1 
Liu, Z., Li, N., and Neu, J. (2005). Tight junctions, leaky intestines, and pediatric diseases. Acta Paediatr. 94, 386-393. doi: 10.1111/j.1651-2227.2005.tb01904.x

Luo, X. M., Edwards, M. R., Mu, Q., Yu, Y., Vieson, M. D., Reilly, C. M., et al. (2018), Gut microbiota in human systemic lupus erythematosus and a mouse model of lupus. Appl. Environ. Microbiol. 84:e2288-17. doi: 10.1128/AEM.02288-17

MacDonald, J. L., and Roskams, A. J. (2009). Epigenetic regulation of nervous system development by DNA methylation and histone deacetylation. Prog. Neurobiol. 88, 170-183. doi: 10.1016/j.pneurobio.2009.04.002

Machado, C. J., Whitaker, A. M., Smith, S. E., Patterson, P. H., and Bauman, M. D. (2015). Maternal immune activation in nonhuman primates alters social attention in juvenile offspring. Biol. Psychiatry 77, 823-832. doi: 10.1016/j. biopsych.2014.07.035

Macpherson, A. J., de Agüero, M. G., and Ganal-Vonarburg, S. C. (2017). How nutrition and the maternal microbiota shape the neonatal immune system. Nat. Rev. Immunol. 17, 508-517. doi: 10.1038/nri.2017.58

Malkova, N. V., Yu, C. Z., Hsiao, E. Y., Moore, M. J., and Patterson, P. H. (2012). Maternal immune activation yields offspring displaying mouse versions of the three core symptoms of autism. Brain Behav. Immun. 26, 607-616. doi: 10.1016/ j.bbi.2012.01.011

Mardinoglu, A., Shoaie, S., Bergentall, M., Ghaffari, P., Zhang, C., Larsson, E., et al. (2015). The gut microbiota modulates host amino acid and glutathione metabolism in mice. Mol. Syst. Biol. 11:834. doi: 10.15252/msb.2015 6487

Marieb, E. N., and Hoen, K. (2007). Human Anatomy and Physiology. San Francisco, CA: Pearson Benjamin Cummings.

Martin, R., Makino, H., Cetinyurek Yavuz, A., Ben-Amor, K., Roelofs, M., Ishikawa, E., et al. (2016). Early-life events, including mode of delivery and type of feeding, siblings and gender, shape the developing gut microbiota. PLoS One 11:e0158498. doi: 10.1371/journal.pone.0158498

Masi, A., Glozier, N., Dale, R., and Guastella, A. J. (2017). The immune system, cytokines, and biomarkers in autism spectrum disorder. Neurosci. Bull. 33, 194-204. doi: 10.1007/s12264-017-0103-8

McBean, G. J. (2017). Cysteine, glutathione, and thiol redox balance in astrocytes. Antioxidants 6:E62. doi: 10.3390/antiox6030062

McCall, C. E., Yoza, B., Liu, T., and El Gazzar, M. (2010). Gene-specific epigenetic regulation in serious infections with systemic inflammation. J. Innate Immun. 2, 395-405. doi: 10.1159/000314077

Meehan, R. R., Thomson, J. P., Lentini, A., Nestor, C. E., and Pennings, S. (2018). DNA methylation as a genomic marker of exposure to chemical and environmental agents. Curr. Opin. Chem. Biol. 45, 48-56. doi: 10.1016/j.cbpa. 2018.02.006

Meyer, J. N., Leung, M. C., Rooney, J. P., Sendoel, A., Hengartner, M. O., Kisby, G. E., et al. (2013). Mitochondria as a target of environmental toxicants. Toxicol. Sci. 134, 1-17. doi: 10.1093/toxsci/kft102

Mirza, A., and Mao-Draayer, Y. (2017). The gut microbiome and microbial translocation in multiple sclerosis. Clin. Immunol. 183, 213-224. doi: 10.1016/j. clim.2017.03.001

Mittal, R., Debs, L. H., Patel, A. P., Nguyen, D., Patel, K., O’Connor, G., et al. (2017). Neurotransmitters: the critical modulators regulating gut-brain axis. J. Cell. Physiol. 232, 2359-2372. doi: 10.1002/jcp.25518

Moosa, A., Shu, H., Sarachana, T., and Hu, V. W. (2017). Are endocrine disrupting compounds environmental risk factors for autism spectrum disorder? Horm. Behav. 101, 13-21. doi: 10.1016/j.yhbeh.2017.10.003

Morén, C., Juárez-Flores, D. L., Cardellach, F., and Garrabou, G. (2016). The role of therapeutic drugs on acquired mitochondrial toxicity. Curr. Drug Metab. 17, 648-662. doi: 10.2174/1389200217666160322143631

Morgan, J. T., Chana, G., Pardo, C. A., Achim, C., Semendeferi, K., Buckwalter, J., et al. (2010). Microglial activation and increased microglial density observed in the dorsolateral prefrontal cortex in autism. Biol. Psychiatry 68, 368-376. doi: 10.1016/j.biopsych.2010.05.024

Morgun, A., Dzutsev, A., Dong, X., Greer, R. L., Sexton, D. J., Ravel, J., et al. (2015). Uncovering effects of antibiotics on the host and microbiota using transkingdom gene networks. Gut 64, 1732-1743. doi: 10.1136/gutjnl-2014308820

Moya-Pérez, A., Luczynski, P., Renes, I. B., Wang, S., Borre, Y., Anthony Ryan, C., et al. (2017). Intervention strategies for cesarean section-induced alterations in the microbiota-gut-brain axis. Nutr. Rev. 75, 225-240. doi: 10.1093/nutrit/ nuw069
Murray, M. T. (2013). "5-Hydroxytryptophan," in Textbook of Natural Medicine, 4th Edn, eds J. E. Pizzorno and M. T. Murray (St. Louis, MO: Elsevier Churchill Livingstone), 98. doi: 10.1016/B978-1-4377-2333-5.00098-5

Napoli, E., Wong, S., Hertz-Picciotto, I., and Giulivi, C. (2014). Deficits in bioenergetics and impaired immune response in granulocytes from children with autism. Pediatrics 133, e1405-e1410. doi: 10.1542/peds.2013-1545

Nardone, S., Sams, D. S., Zito, A., Reuveni, E., and Elliott, E. (2017). Dysregulation of cortical neuron DNA methylation profile in autism spectrum disorder. Cereb. Cortex 27, 5739-5754. doi: 10.1093/cercor/bhx250

Naser, S. A., Arce, M., Khaja, A., Fernandez, M., Naser, N., Elwasila, S., et al. (2012). Role of ATG16L, NOD2 and IL23R in Crohn's disease pathogenesis. World J. Gastroenterol. 18, 412-424. doi: 10.3748/wjg.v18.i5.412

Neu, J., and Rushing, J. (2011). Cesarean versus vaginal delivery: long-term infant outcomes and the hygiene hypothesis. Clin. Perinatol. 38, 321-331. doi: 10. 1016/j.clp.2011.03.008

Ni, J., Wu, G. D., Albenberg, L., and Tomov, V. T. (2017). Gut microbiota and IBD: causation or correlation? Nat. Rev. Gastroenterol. Hepatol. 14, 573-584. doi: $10.1038 /$ nrgastro.2017.88

Niehus, R., and Lord, C. (2006). Early medical history of children with autism spectrum disorders. J. Dev. Behav. Pediatr. 27, 120-S127. doi: 10.1097/ 00004703-200604002-00010

Obermeier, B., Verma, A., and Ransohoff, R. M. (2016). The blood-brain barrier. Handb. Clin. Neurol. 133, 39-59. doi: 10.1016/B978-0-444-63432-0.00003-7

Ochoa-Repáraz, J., and Kasper, L. H. (2014). Gut microbiome and the risk factors in central nervous system autoimmunity. FEBS Lett. 588, 4214-4222. doi: 10. 1016/j.febslet.2014.09.024

Olivier, B. (2015). Serotonin: a never-ending story. Eur. J. Pharmacol. 753, 2-18. doi: 10.1016/j.ejphar.2014.10.031

Parracho, H., Bingham, M. O., Gibson, G. R., and McCartney, A. L. (2005). Differences between the gut microflora of children with autistic spectrum disorders and that of healthy children. J. Med. Microbiol. 54, 987-991. doi: 10.1099/jmm.0.46101-0

Pérez-Cobas, A. E., Gosalbes, M. J., Friedrichs, A., Knecht, H., Artacho, A., Eismann, K., et al. (2013). Gut microbiota disturbance during antibiotic therapy: a multi-omic approach. Gut 62, 1591-1601. doi: 10.1136/gutjnl-2012303184

Pilling, O. A., Rogers, A. J., Gulla-Devaney, B., and Katz, L. A. (2017). Insights into transgenerational epigenetics from studies of ciliates. Eur. J. Protistol. 61, 366-375. doi: 10.1016/j.ejop.2017.05.004

Ponziani, F. R., Scaldaferri, F., Petito, V., Paroni Sterbini, F., Pecere, S., Lopetuso, L. R., et al. (2016). The role of antibiotics in gut microbiota modulation: the eubiotic effects of rifaximin. Dig. Dis. 34, 269-278. doi: 10.1159/000443361

Qin, J., Li, Y., Cai, Z., Li, S., Zhu, J., Zhang, F., et al. (2012). A metagenomewide association study of gut microbiota in type 2 diabetes. Nature 490, 55-60. doi: 10.1038/nature11450

Rai, V. (2016). Association of methylenetetrahydrofolate reductase (MTHFR) gene C677T polymorphism with autism: evidence of genetic susceptibility. Metab. Brain Dis. 31, 727-735. doi: 10.1007/s11011-016-9815-0

Rai, V. (2017). Methylenetetrahydrofolate Reductase (MTHFR) C677T polymorphism and alzheimer disease risk: a meta-analysis. Mol. Neurobiol. 54 1173-1186. doi: 10.1007/s12035-016-9722-8

Rakoff-Nahoum, S., Paglino, J., Eslami-Varzaneh, F., Edberg, S., and Medzhitov, R. (2004). Recognition of commensal microflora by toll-like receptors is required for intestinal homeostasis. Cell 118, 229-241. doi: 10.1016/j.cell.2004.07.002

Reigstad, C. S., Salmonson, C. E., Rainey, J. F. III, Szurszewski, J. H., Linden, D. R., Sonnenburg, J. L., et al. (2015). Gut microbes promote colonic serotonin production through an effect of short-chain fatty acids on enterochromaffin cells. FASEB J. 29, 1395-1403. doi: 10.1096/fj.14-259598

Rose, D. R., Yang, H., Serena, G., Sturgeon, C., Ma, B., Careaga, M., et al. (2018). Differential immune responses and microbiota profiles in children with autism spectrum disorders and co-morbid gastrointestinal symptoms. Brain Behav. Immun. 70, 354-368. doi: 10.1016/j.bbi.2018.03.025

Rosen, M. J., Dhawan, A., and Saeed, S. A. (2015). Inflammatory bowel disease in children and adolescents. JAMA Pediatr. 169, 1053-1060. doi: 10.1001/ jamapediatrics.2015.1982

Rossignol, D. A., and Frye, R. E. (2014). Evidence linking oxidative stress, mitochondrial dysfunction, and inflammation in the brain of individuals with autism. Front. Physiol. 5:150. doi: 10.3389/fphys.2014.00150 
Roubroeks, J. A. Y., Smith, R. G., van den Hove, D. L. A., and Lunnon, K. (2017). Epigenetics and DNA methylomic profiling in Alzheimer's disease and other neurodegenerative diseases. J. Neurochem. 143, 158-170. doi: 10.1111/jnc. 14148

Rutten, N. B., Rijkers, G. T., Meijssen, C. B., Crijns, C. E., Oudshoorn, J. H., van der Ent, C. K., et al. (2015). Intestinal microbiota composition after antibiotic treatment in early life: the INCA study. BMC Pediatr. 15:204. doi: 10.1186/ s12887-015-0519-0

Samanta, S., Rajasingh, S., Cao, T., Dawn, B., and Rajasingh, J. (2017). Epigenetic dysfunctional diseases and therapy for infection and inflammation. Biochim. Biophys. Acta 1863, 518-528. doi: 10.1016/j.bbadis.2016.11.030

Saunders, N. R., Liddelow, S. A., and Dziegielewska, K. M. (2012). Barrier mechanisms in the developing brain. Front. Pharmacol. 3:46. doi: 10.3389/ fphar.2012.00046

Segen, J. C. (2005). Concise Dictionary of Modern Medicine, 2nd Edn. New York, NY: McGraw-Hill.

Sharma, A. (2017). Transgenerational epigenetics: integrating soma to germline communication with gametic inheritance. Mech. Ageing Dev. 163, 15-22. doi: 10.1016/j.mad.2016.12.015

Shively, C. A., Silverstein-Metzler, M., Justice, J., and Willard, S. L. (2017). The impact of treatment with selective serotonin reuptake inhibitors on primate cardiovascular disease, behavior, and neuroanatomy. Neurosci. Biobehav. Rev. 74(Pt B), 433-443. doi: 10.1016/j.neubiorev.2016.08.037

Simon, A. K., Hollander, G. A., and McMichael, A. (2015). Evolution of the immune system in humans from infancy to old age. Proc. Biol. Sci. 282:20143085. doi: 10.1098/rspb.2014.3085

Siu, M. T., and Weksberg, R. (2017). Epigenetics of autism spectrum disorder. Adv. Exp. Med. Biol. 978, 63-90. doi: 10.1007/978-3-319-53889-1_4

Smith, E. F., Shaw, P. J., and De Vos, K. J. (2017). The role of mitochondria in amyotrophic lateral sclerosis. Neurosci. Lett. [Epub ahead of print].

Smith, S. E. P., Li, J., Garbett, K., Mirnics, K., and Patterson, P. H. (2007). Maternal immune activation alters fetal brain development through interleukin-6. J. Neurosci. 27, 10695-10702. doi: 10.1523/JNEUROSCI.2178-07.2007

Sobhani, I., Tap, J., Roudot-Thoraval, F., Roperch, J. P., Letulle, S., Langella, P., et al. (2011). Microbial dysbiosis in colorectal cancer (CRC) patients. PLoS One 6:e16393. doi: 10.1371/journal.pone.0016393

Son, J. S., Zheng, L. J., Rowehl, L. M., Tian, X., Zhang, Y., Zhu, W., et al. (2015). Comparison of fecal microbiota in children with autism spectrum disorders and neurotypical siblings in the simons simplex collection. PLoS One 10:e0137725. doi: 10.1371/journal.pone.0137725

Stolp, H. B., Ek, C. J., Johansson, P. A., Dziegielewska, K. M., Bethge, N., Wheaton, B. J., et al. (2009). Factors involved in inflammation-induced developmental white matter damage. Neurosci. Lett. 451, 232-236. doi: 10.1016/j.neulet.2009. 01.021

Stolp, H. B., Johansson, P. A., Habgood, M. D., Dziegielewska, K. M., Saunders, N. R., and Ek, C. J. (2011). Effects of neonatal systemic inflammation on bloodbrain barrier permeability and behaviour in juvenile and adult rats. Cardiovasc. Psychiatry Neurol. 2011:469046. doi: 10.1155/2011/469046

Strati, F., Cavalieri, D., Albanese, D., De Felice, C., Donati, C., Hayek, J., et al. (2017). New evidences on the altered gut microbiota in autism spectrum disorders. Microbiome 5:24. doi: 10.1186/s40168-017-0242-1

Sturgeon, C., Lan, J., and Fasano, A. (2017). Zonulin transgenic mice show altered gut permeability and increased morbidity/mortality in the DSS colitis model. Ann. N. Y. Acad. Sci. 1397, 130-142. doi: 10.1111/nyas.13343

Sylvia, K. E., and Demas, G. E. (2018). A gut feeling: microbiome-brain-immune interactions modulate social and affective behaviors. Horm. Behav. 99, 41-49. doi: 10.1016/j.yhbeh.2018.02.001

Taylor, R. W., and Turnbull, D. M. (2005). Mitochondrial DNA mutations in human disease. Nat. Rev. Genet. 6, 389-402. doi: 10.1038/nrg1606

Thursby, E., and Juge, N. (2017). Introduction to the human gut microbiota. Biochem. J. 474, 1823-1836. doi: 10.1042/BCJ20160510

Tran, N. Q. V., and Miyake, K. (2017). Neurodevelopmental disorders and environmental toxicants: epigenetics as an underlying mechanism. Int. J. Genomics 2017:7526592. doi: 10.1155/2017/7526592

Turck, D., and Michaud, L. (2008). "Lower gastrointestinal bleeding," in Walker's Pediatric Gastroenterologic Diseases: Pathophysiology, Diagnosis, Management, 5th Edn, Vol. 2, eds R. E. Kleinman, O.-J. Goulet, and G. Mieli-Vergani (Hamilton: BC Decker).
Turnbaugh, P. J., Hamady, M., Yatsunenko, T., Cantarel, B. L., Duncan, A., Ley, R. E., et al. (2009). A core gut microbiome in obese and lean twins. Nature 457, 480-484. doi: 10.1038/nature07540

Turnbaugh, P. J., Ley, R. E., Mahowald, M. A., Magrini, V., Mardis, E. R., and Gordon, J. I. (2006). An obesity-associated gut microbiome with increased capacity for energy harvest. Nature 444, 1027-1031. doi: 10.1038/nature 05414

Ubeda, C., Taur, Y., Jenq, R. R., Equinda, M. J., Son, T., Samstein, M., et al. (2010). Vancomycin-resistant Enterococcus domination of intestinal microbiota is enabled by antibiotic treatment in mice and precedes bloodstream invasion in humans. J. Clin. Invest. 120, 4332-4341. doi: 10.1172/JCI43918

United States Department of Health and Human Services (2016). United States Department of Agriculture. 2015-2020 Dietary Guidelines for Americans, 8th Edn. Available at: health.gov/dietaryguidelines/2015/guidelines/ [accessed 15 January, 2016].

Urbaniak, C., Angelini, M., Gloor, G. B., and Reid, G. (2016). Human milk microbiota profiles in relation to birthing method, gestation and infant gender. Microbiome 4:1. doi: 10.1186/s40168-015-0145-y

Verity, C. M., Winstone, A. M., Stellitano, L., Krishnakumar, D., Will, R., and McFarland, R. (2010). The clinical presentation of mitochondrial diseases in children with progressive intellectual and neurological deterioration: a national, prospective, population-based study. Dev. Med. Child Neurol. 52, 434-440. doi: 10.1111/j.1469-8749.2009.03463.x

Virzì, G. M., Clementi, A., Brocca, A., de Cal, M., and Ronco, C. (2018). Epigenetics: a potential key mechanism involved in the pathogenesis of cardiorenal syndromes. J. Nephrol. 31, 333-341. doi: 10.1007/s40620-017-0425-7

Vojdani, A., Mumper, E., Granpeesheh, D., Mielke, L., Traver, D., Bock, K., et al. (2008). Low natural killer cell cytotoxic activity in autism: the role of glutathione, IL-2 and IL-15. J. Neuroimmunol. 205, 148-154. doi: 10.1016/j. jneuroim.2008.09.005

Waly, M. I., Hornig, M., Trivedi, M., Hodgson, N., Kini, R., Ohta, A., et al. (2012). Prenatal and postnatal epigenetic programming: implications for GI, immune, and neuronal function in autism. Autism Res. Treat. 2012:190930. doi: $10.1155 / 2012 / 190930$

Wang, L., Christophersen, C. T., Sorich, M. J., Gerber, J. P., Angley, M. T., and Conlon, M. A. (2012). Elevated fecal short chain fatty acid and ammonia concentrations in children with autism spectrum disorder. Dig. Dis. Sci. 57, 2096-2102. doi: 10.1007/s10620-012-2167-7

Wang, L. W., Tancredi, D. J., and Thomas, D. W. (2011). The prevalence of gastrointestinal problems in children across the United States with autism spectrum disorders from families with multiple affected members. J. Dev. Behav. Pediatr. 32, 351-360. doi: 10.1097/DBP.0b013e31821bd06a

Wang, Q., Ito, M., Adams, K., Li, B. U., Klopstock, T., Maslim, A., et al. (2004). Mitochondrial DNA control region sequence variation in migraine headache and cyclic vomiting syndrome. Am. J. Med. Genet. A 131, 50-58. doi: 10.1002/ ajmg.a.30323

Wang, W., Uzzau, S., Goldblum, S. E., and Fasano, A. (2000). Human zonulin, a potential modulator of intestinal tight junctions. J. Cell. Sci. 113, 4435-4440.

Wang, W. M., and Jin, H. Z. (2017). Homocysteine: a potential common route for cardiovascular risk and DNA methylation in psoriasis. Chin. Med. J. 130, 1980-1986. doi: 10.4103/0366-6999.211895

Wang, Y., Wu, Y., Wang, Y., Xu, H., Mei, X., Yu, D., et al. (2017). Antioxidant properties of probiotic bacteria. Nutrients 9:521. doi: 10.3390/nu9050521

Wątroba, M., Dudek, I., Skoda, M., Stangret, A., Rzodkiewicz, P., and Szukiewicz, D. (2017). Sirtuins, epigenetics and longevity. Ageing Res. Rev. 40, 11-19. doi: 10.1016/j.arr.2017.08.001

Waye, M. M. Y., and Cheng, H. Y. (2018). Genetics and epigenetics of autism: a review. Psychiatry Clin. Neurosci. 72, 228-244. doi: 10.1111/pcn.12606

Weber, C. R. (2012). Dynamic properties of the tight junction barrier. Ann. N. Y. Acad. Sci. 1257, 77-84. doi: 10.1111/j.1749-6632.2012.06528.x

Whitaker-Azmitia, P. M. (2001). Serotonin and brain development: role in human developmental diseases. Brain Res. Bull. 56, 479-485. doi: 10.1016/S03619230(01)00615-3

Williams, B. L., Hornig, M., Parekh, T., and Lipkin, W. I. (2012). Application of novel PCR-based methods for detection, quantitation, and phylogenetic characterization of Sutterella species in intestinal biopsy samples from children with autism and gastrointestinal disturbances. mBio 3:e261-11. doi: 10.1128/ mBio.00261-11 
Wong, C. C., Meaburn, E. L., Ronald, A., Price, T. S., Jeffries, A. R., Schalkwyk, L. C., et al. (2014). Methylomic analysis of monozygotic twins discordant for autism spectrum disorder and related behavioural traits. Mol. Psychiatry 19, 495-503. doi: $10.1038 / \mathrm{mp} .2013 .41$

Wong, H., and Hoeffer, C. (2017). Maternal IL-17A in autism. Exp. Neurol. 299(Pt A), 228-240. doi: 10.1016/j.expneurol.2017.04.010

Yamanaka, T., Helgeland, L., Farstad, I. N., Fukushima, H., Midtvedt, T., and Brandtzaeg, P. (2003). Microbial colonization drives lymphocyte accumulation and differentiation in the follicle-associated epithelium of Peyer's patches. J. Immunol. 170, 816-822. doi: 10.4049/jimmunol.170.2.816

Yang, L., Lu, X., Nossa, C. W., Francois, F., Peek, R. M., and Pei, Z. (2009). Inflammation and intestinal metaplasia of the distal esophagus are associated with alterations in the microbiome. Gastroenterology 137, 588-597. doi: 10. 1053/j.gastro.2009.04.046

Yano, J. M., Yu, K., Donaldson, G. P., Shastri, G. G., Ann, P., Ma, L., et al. (2015). Indigenous bacteria from the gut microbiota regulate host serotonin biosynthesis. Cell 161, 264-276. doi: 10.1016/j.cell.2015.02.047

Young, S. N. (2007). How to increase serotonin in the human brain without drugs. J. Psychiatry Neurosci. 32, 394-399.

Yuan, Y., Yu, X., Niu, F., and Lu, N. (2017). Genetic polymorphism of methylenetetrahydrofolate reductase as a potential risk factor for congenital heart disease: a meta-analysis in Chinese pediatric population. Medicine 96:e7057. doi: 10.1097/MD.0000000000007057
Zhang, X., Hu, M., Lyu, X., Li, C., Thannickal, V. J., and Sanders, Y. Y. (2017). DNA methylation regulated gene expression in organ fibrosis. Biochim. Biophys. Acta 1863, 2389-2397. doi: 10.1016/j.bbadis.2017.05.010

Zhang, X., Zhang, D., Jia, H., Feng, Q., Wang, D., Liang, D., et al. (2015). The oral and gut microbiomes are perturbed in rheumatoid arthritis and partly normalized after treatment. Nat. Med. 21, 895-905. doi: 10.1038/nm. 3914

Ziv-Gal, A., Wang, W., Zhou, C., and Flaws, J. A. (2015). The effects of in utero bisphenol A exposure on reproductive capacity in several generations of mice. Toxicol. Appl. Pharmacol. 284, 354-362. doi: 10.1016/j.taap.2015. 03.003

Conflict of Interest Statement: The authors declare that the research was conducted in the absence of any commercial or financial relationships that could be construed as a potential conflict of interest.

Copyright ( 2018 Eshraghi, Deth, Mittal, Aranke, Kay, Moshiree and Eshraghi. This is an open-access article distributed under the terms of the Creative Commons Attribution License (CC BY). The use, distribution or reproduction in other forums is permitted, provided the original author(s) and the copyright owner(s) are credited and that the original publication in this journal is cited, in accordance with accepted academic practice. No use, distribution or reproduction is permitted which does not comply with these terms. 